\title{
Ultrasonic Instrumentation Instruction in Dental Hygiene Programs in the United States
}

Sharon Lee Stemple Hinchman

West Virginia University

Follow this and additional works at: https://researchrepository.wvu.edu/etd

\section{Recommended Citation}

Hinchman, Sharon Lee Stemple, "Ultrasonic Instrumentation Instruction in Dental Hygiene Programs in the United States" (2011). Graduate Theses, Dissertations, and Problem Reports. 131.

https://researchrepository.wvu.edu/etd/131

This Thesis is protected by copyright and/or related rights. It has been brought to you by the The Research Repository @ WVU with permission from the rights-holder(s). You are free to use this Thesis in any way that is permitted by the copyright and related rights legislation that applies to your use. For other uses you must obtain permission from the rights-holder(s) directly, unless additional rights are indicated by a Creative Commons license in the record and/ or on the work itself. This Thesis has been accepted for inclusion in WVU Graduate Theses, Dissertations, and Problem Reports collection by an authorized administrator of The Research Repository @ WVU. For more information, please contact researchrepository@mail.wvu.edu. 
Ultrasonic Instrumentation Instruction in Dental Hygiene Programs in the United States

Sharon Lee Stemple Hinchman, RDH, BS

\author{
Thesis submitted to the \\ School of Dentistry \\ at West Virginia University \\ in partial fulfillment of the requirements \\ for the degree of
}

Master of Science

in

Dental Hygiene
Christina DeBiase, BSDH, MA, EdD, Chair
Cathryn Frere, BSDH, MSEd
Amy Funk, BSDH, MSDH
Division of Dental Hygiene

Morgantown, West Virginia

2011

Key Words: Ultrasonic; Magnetostrictive; Piezoelectric 


\author{
ABSTRACT \\ Ultrasonic Instrumentation Instruction in Dental Hygiene Programs \\ in the United States \\ Sharon Stemple Hinchman
}

The purpose of this study is to determine the existence and extent of ultrasonic scaling instrumentation instruction in dental hygiene programs nationally. Currently, there is no research available defining a consensus of instruction for ultrasonic instrumentation in dental hygiene programs. An email survey was sent to all directors of dental hygiene programs in the United States $(n=323)$. The response rate was $45 \%$. No significant differences in methods or extent of instruction were found between associate and baccalaureate degree granting programs. Eightynine percent of programs introduce hand scaling prior to ultrasonic scaling instrumentation instruction. Students in $96 \%$ of the programs are required to administer a pre-procedural mouth rinse reducing the amount of bacteria that would potentially be released in the aerosol produced. A variety of resources and strategies are employed for teaching ultrasonic instrumentation and competency is measured in several ways. The availability of magnetostrictive ultrasonic scalers is much greater than that of piezoelectric ultrasonic scalers in the student clinics. Programs use a variety of inserts and tips and some programs require students to purchase magnetostrictive ultrasonic units. The results of this study show that ultrasonic instrumentation is an integral component of the clinical curriculum and the majority of the dental hygiene programs prescribe to similar teaching methods, use the same textbooks, teach the same adaption techniques and strokes and use typodonts, student partners and onsite patients. 


\section{Dedication}

To my husband, Mike and my children, Kristin and Andrew for constant support, patience, encouragement and love. You share my joy in achieving my ultimate goal. To my brother, Alan D. Stemple, PhD, Aerospace Engineering, for his statistical help and encouragement, having traveled this path before me. I love you all.

In memory of my mother, (Phyllis) Carmella Lee Cavalier Stemple.

In memory of my paternal grandparents, Paul and Opal Stemple, who were educators, stretching the minds of hundreds of students. 


\section{ACKNOWLEDGEMENTS}

I want to express my sincere gratitude to my thesis committee: Christina DeBiase, EdD, Amy Funk, MSDH and Cathryn Frere, BSDH, MSEd for your support, guidance, advice and time. Thank you to Marie George, MSDH for your knowledgeable guidance with the literature review. 


\section{TABLE OF CONTENTS}

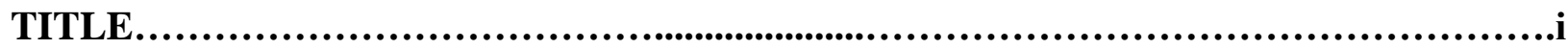

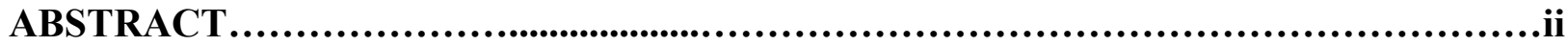

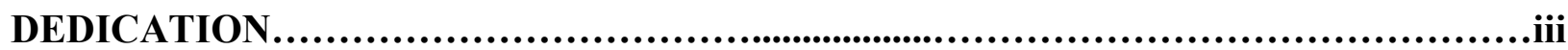

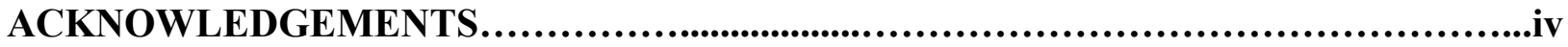

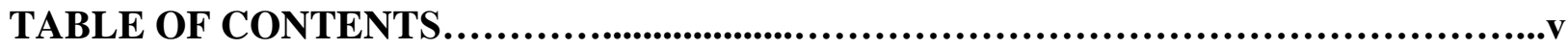

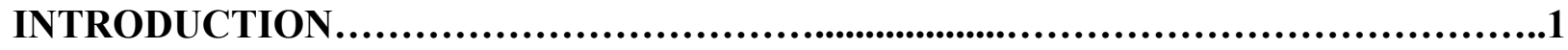

REVIEW OF LITERATURE.................................................................

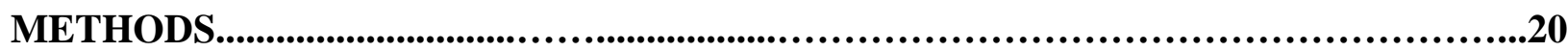

RESULTS.........................................................................................................................................................23

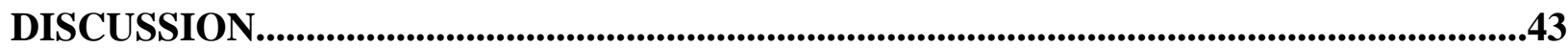

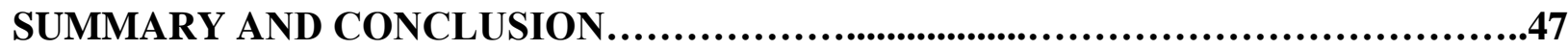

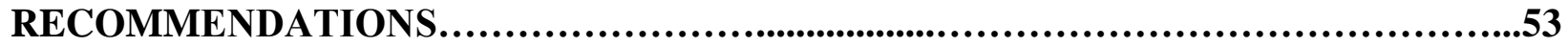

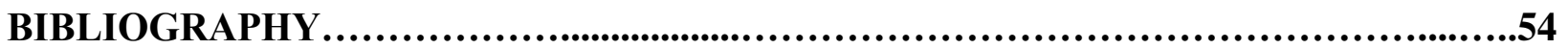

APPENDIX A IRB letter.............................................................................60

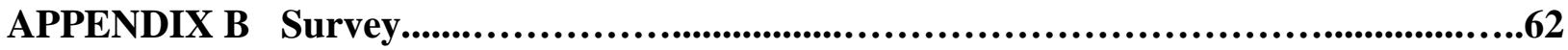

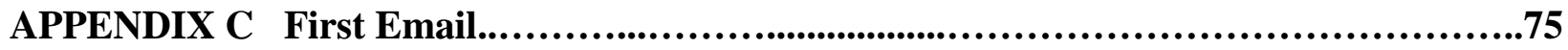

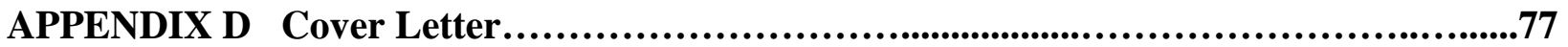

APPENDIX E Second Email...........................................................................79

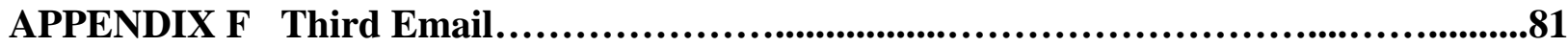

CURRICULUM VITAE.................................................................................................................83 
Ultrasonic Instrumentation Instruction in Dental Hygiene Programs

In the United States

\section{Chapter One}

\section{Introduction}

Ongoing research of periodontal disease has provided the professional community with a comprehensive foundation of information, which has led to significant improvements in effective treatment options. Management of periodontal disease includes understanding the association between systemic health and oral health along with understanding available therapeutic treatment. Historically, periodontal scaling and root planing were accomplished using hand instruments because ultrasonic scalers were designed for gross scaling and removal of supragingival calculus and stains. The tips of ultrasonic scalers originally were too large to fit into the sulcus around the tooth. ${ }^{1-2,4}$ One effective treatment option is the use of an ultrasonic scaler with longer, thinner tips. A body of evidence supports the efficacy of ultrasonic instrumentation as a valuable component of periodontal therapy. ${ }^{3}$

Ultrasonic scalers are considered power-driven. ${ }^{4}$ There are two types of ultrasonic scalers, magnetostrictive and piezoelectric. These devices use different mechanisms for producing the vibration of the working end. Ultrasonic scalers have been proven through evidence-based research to be an effective tool for the treatment of periodontal disease as well as for removal of all calculus, biofilms and pathogens. ${ }^{4}$ 
Ultrasonic scalers have been in use for over fifty years. The rationale for their use has changed due to evidence-based study of the results of using an ultrasonic scaler, more in depth research and study of periodontal disease. There have been many new inserts and tips developed to provide more therapeutic treatment of patients.

No studies, to date, have been conducted that compare how dental hygiene programs in the United States approach the teaching of ultrasonic scalers. Several textbooks include written instructions for the proper use of ultrasonic scalers along with pictures and diagrams. Learning to use an ultrasonic scaler properly and effectively requires learning the morphology of the teeth. Students must learn to identify that part of the tip or insert that is the active working surface in order to understand how to properly adapt the tip or insert to the tooth effectively. Learning objectives usually include the mechanism of the ultrasonic instrumentation, the rationale for selecting a variety of tips or inserts, the proper instrumentation of the tooth, the process of periodontal disease, and the therapeutic treatment options available. The majority of clinicians are first exposed to the ultrasonic scaler while a student in a dental hygiene program.

\section{Statement of the Problem}

The purpose of this study is to provide a comprehensive overview of current ultrasonic instrumentation teaching methods used in dental hygiene programs in the United States. Currently, there is no research available defining a consensus of teaching methods for ultrasonic instrumentation in dental hygiene programs in the United States.

\section{Significance of the Study}

This study is important due to the vast changes in philosophy and treatment of periodontal disease. Dental hygiene programs are expected to teach content on ultrasonic instrumentation for periodontal therapy that is current and evidence-based. Ideally, instruction would include the 
therapeutic mechanism of the ultrasonic action, ultrasonic instrumentation technique including the adaptation of various tips or inserts, the rationale and criteria for use of tips or inserts, infection control, pain management and the application of these principles through actual clinical experience. Competency would be gained through clinical experience after learning tooth morphology, proper adaptation of tips or inserts, and how the shape of the tip or insert functions in relation to the tooth structure. In addition, some mechanism for evaluation of student competency would be expected. Results of this study will allow dental hygiene programs to compare their practices for teaching ultrasonic instrumentation with those of other programs in the United States. The information provided should assist in reevaluating portions of their ultrasonic curriculum while validating other segments of instruction to establish consistency of theory and practice.

\section{Questions to be Answered}

When comparing the focus of dental hygiene programs' instrumentation instruction in the United States, the following questions need to be answered.

1. What emphasis do programs place on ultrasonic scaling instrumentation compared to that placed on hand scaling?

2. When is ultrasonic instrumentation introduced relative to hand scaling?

3. What resources and strategies are employed for teaching ultrasonic instrumentation?

4. What criteria are given for choosing the use of an ultrasonic scaler?

5. How is student competency in the use of ultrasonic scalers determined?

6. What is the availability of ultrasonic units for student use?

7. What tips or inserts do programs most frequently use? 
8. Are magnetostrictive and piezoelectric ultrasonic units equally available?

9. What methods are used to control the bacteria laden aerosol produced by the ultrasonic scaler?

\section{Definitions}

Acoustic turbulence: The agitation of fluid produce by the rapid vibration of an ultrasonic tip.

Cavitation: The creation and subsequent collapse of bubbles in the water from the ultrasonic tip that is due to high frequency sound waves produced by the vibration at the working tip. The bubbles release energy as they collapse.

Lavage: The therapeutic rinsing of the sulcus surrounding the tooth and the root surfaces with the purpose of flushing out microorganisms, endotoxins and loose debris.

Debridement: The removal of subgingival calculus, attached biofilm, and endotoxins from the root surface and the unattached biofilm from the sulcus.

\section{Assumptions}

1. All dental hygiene faculty are familiar with and know the differences between sonic scalers, magnetostrictive and piezoelectric ultrasonic scalers.

2. The individual completing the survey is the most knowledgeable resource about the program's ultrasonic instruction.

3. All dental hygiene programs teach both didactic and clinical ultrasonic instruction. 
4. Students are taught:

a. The role of systemic risks factors along with other risk factors that contribute to periodontal disease.

b. The tooth morphology, necessary to understand proper adaptation techniques for effective hand and ultrasonic instrumentation.

c. Proper hand instrumentation of teeth.

d. The mechanics of ultrasonic scalers.

e. Selection of inserts and tip appropriate for type of deposit and anatomy of treatment site.

f. The criteria for choosing an ultrasonic scaler.

g. The evidence-based treatment outcomes resulting from use of an ultrasonic scaler.

5. Competency will be measured by evaluating student performance using the ultrasonic scaler.

\section{Limitations}

1. The first survey was sent on May 31, 2011, which may be between spring and summer sessions. Some dental hygiene programs are not in session during the summer months, which would limit the response of program directors.

2. The timing of the second email of the survey coincided with the American Dental Education Association Allied Program Directors' Conference followed by the American Dental Hygienists' Association annual session.

3. Email addresses may no longer be valid.

4. Emails may be sent to junk mail files and program directors may not check or open perceived junk email. 
5. Some program directors refuse to answer surveys.

\section{Delimitations}

1. All accredited dental hygiene programs provided in a list from the American Dental Hygienists' Association website.

2. The survey provided questions with multiple-choice answers and open-ended questions along with options to add comments or answers that might not have been included in the choices listed. 


\section{Chapter 2}

\section{Literature Review}

\section{History}

The past 50 years has seen a change in the methods, rational and theory for periodontal debridement. The original goal of periodontal therapy was to completely remove all calculus subgingivally. In 1957, the first commercial device for the removal of calculus was launched starting ultrasonic technology's impact on non-surgical periodontal therapy. ${ }^{1}$ The original ultrasonic units were designed for gross scaling, removal of supragingival calculus. ${ }^{1,4}$

In the 1960s and 1970s, practitioners advocated aggressive hand scaling and root planing with the purpose of achieving a glassy smooth root surface, which resulted in removing pathogens along with excessive amounts of tooth structure. This aggressive debridement also exposed the dentin often resulting in hypersensitivity. ${ }^{4,6}$ Periodontal therapy was a two-step process based on the theory that calculus was an irritant and the source of periodontal disease. The ultrasonic scaler did not plane the root surface well enough for successful periodontal therapy therefore it was viewed as an adjunct tool. ${ }^{4}$ Gross scaling, the first part of the process in which the calculus was removed with the ultrasonic scaler, was followed by fine hand scaling to bring the tooth to a glassy smooth surface. Gracey curets used in the 1970s were effective in achieving the glassy smooth root surface. ${ }^{6}$ Results of such scaling were: removing excessive cementum, reducing the tooth to an hourglass shape and increasing root sensitivity. This twostep procedure resulted in trapping pathogens leading to periodontal abscesses, as the tissue healed over the disease sulcus. ${ }^{6}$ The gingival tissues healing resulted in limited access to areas of infection in the sulcus. $^{2}$ The role of bacteria was unclear during this period. ${ }^{2}$ 
In the 1980s and 1990s, the pendulum moved in the opposite direction advocating the use of ultrasonic scalers on low power, which resulted in burnished calculus with some initial improvement in tissue appearance. ${ }^{7}$ A paradigm shift declared biofilm and free-flowing planktonic bacteria as the cause of infection in the periodontium and surmise it could be treated effectively with ultrasonics on low power. ${ }^{2}$ The tooth structure was preserved along with pathogens, which produced soft tissue ulcerations over burnished deposits resulting in chronic inflammation. Slim-diameter instrument tips were introduced in the late 1980s that were thinner than traditional curet blades. ${ }^{5}$ Smart et al, did an in vitro study of conservative therapy with ultrasonic scaling of the root surface. They found that the detoxifying effects were significant with the ultrasonic debridement, which suggested that conventional root surface instrumentation was unnecessary. ${ }^{6}$ In 1993, the term debridement was introduced to dental hygiene students in the fourth edition of Comprehensive Dental Hygiene Care by Irene Woodall. Debridement addresses treatment of the root surface, the pocket space, the pocket wall, and the underlying tissues, and takes into consideration the immune response of the tissue to that therapy. ${ }^{8}$ This recognizes the bacterial factor and the need to disrupt and remove sources of infection from all pocket surfaces which will allow healing. ${ }^{4,6,8,10}$ By the late 1990 s, the connection between oral health and systemic health and also the connection between oral infection and systemic infection were recognized. Research continues in this area. Related health problems were addressed including premature, low birth weight babies, respiratory infections, diabetes, and endocarditis. ${ }^{12}$

Today, ultrasonic scaling, using a variety of tips designed for reaching deeper into the sulcus, is recommended for the treatment of periodontal disease. The ultrasonic scaler is used on medium to high power to remove the calculus deposits then finishing with an ultrasonic scaler set on medium low power using a thin tip to remove the residual deposits, biofilm and 
endotoxins. Numerous studies have been performed comparing ultrasonic scaling and hand scaling with varying results. At minimum, the two are equal in effectiveness. ${ }^{13-15}$ Ultrasonic scalers require less time to complete subgingival debridement. ${ }^{10,14}$ The ultrasonic scalers have been redesigned with smaller tip diameters and longer shanks to access deep subgingival pocket for disruption of the biofilm, which is necessary for control of periodontal disease. The result is the removal of calculus, biofilms and pathogens from the surfaces of the sulcus walls as well as its contents leaving a surface that is compatible for tissue healing. Ultrasonic slim-diameter instrument tips have been shown to be as effective as hand instruments for removing subgingival calculus deposits, plaque biofilms, and bacterial products from periodontally involved teeth. ${ }^{14}$ Ultrasonic instrumentation using micro-ultrasonic thin tips have been shown to be superior to manual instrumentation when accessing deep, narrow defects and class II and III furcations. ${ }^{10,16}$ Micro-ultrasonic tips are smaller in diameter and can reach deep into the periodontal pocket. ${ }^{17}$

\section{Periodontal Therapy}

The treatment of periodontal disease involves a variety of treatment modalities to stop the infection, remove the microbes, biofilm smear layer and hosts factors to prepare the site for tissue rejuvenation and the return to healthy periodontium. Evidence-based research has definitively determined that the primary etiology of periodontal disease is periodontal pathogens,

not calculus as was once thought. ${ }^{18}$ However, calculus helps create a niche for bacterial growth. The objective is to eliminate subgingival bacteria as much as possible to create a more biologically acceptable environment. It has also been determined that the endotoxins produced by these bacteria are not deeply embedded in the cementum, but are more loosely adhered to the surface of the root and easily removed. ${ }^{12}$ 
The treatment of periodontal disease creates a challenge. New evidence confirms that periodontal disease is more evident in younger people and in general more prevalent than once thought. Pathogens alone do not result in periodontal disease. The host must be susceptible based on the immune system, presence of protective bacteria and presence of pathogenic bacteria to establish the foundation for periodontal disease. ${ }^{14-15,18}$

Inflammation plays a large role in the initiation and progression of periodontal disease. The paradigm shift views periodontal disease as an inflammatory disease of the body. The body's first response to infection is inflammation. This inflammation is not limited to the mouth. It affects the entire body simultaneously. Conversely, inflammation elsewhere in the body affects the mouth. The relationship of systemic health and the inflammatory response must include understanding the risks factors. The bacteria from periodontal disease create byproducts which enter the bloodstream resulting in C-reactive protein being produced by the liver which results in inflammation. ${ }^{19}$ C-reactive protein, which is a nonspecific marker of inflammation is significantly higher in people with periodontal disease. Periodontal disease is related to the immune system and the inflammatory response of an individual. ${ }^{20}$

Mechanical removal of the subgingival microorganisms responsible for periodontal inflammation must be thorough for healing to take place. ${ }^{18}$ Bacteria that create the inflammation will repopulate the subgingival sulcus within weeks beginning within 24-48 hours after removal. Treatment may consist of a combination of hand scaling and power scaling with ultrasonic scalers. The lavage used for ultrasonic instrumentation creates a streaming cavitation resulting in energy release as the bubbles collapse. The cavitation energy creates a disruption of the microbial environment subgingivally. ${ }^{21}$ The microstreaming forces produced by the vibration of the ultrasonic tip creates energy that extends slightly beyond the tip that may result in areas of 
the tooth being inadvertently detoxified..$^{21-22}$ The tip of the ultrasonic instrument may not reach the furcation of the root, but approximately $0.5 \mathrm{~mm}$ beyond that area may still be detoxified. ${ }^{10,21}$ The constant stream of water penetrates to the bottom of the periodontal pocket to flush out the debris, microorganisms, and the endotoxins that have been disrupted. ${ }^{4,21-22}$

\section{Biofilm}

The most effective method for disruption of biofilm is through mechanical means either by hand instrumentation or with the use of power instrumentation. The bacteria that comprise the biofilm are a complex group of microorganisms in a multispecies community. The biofilm or dental plaque is "...characterized by the excretion of an adhesive and protective extracellular matrix, microbe-to-microbe attachment, structural heterogeneity, genetic diversity, and complex community interactions. Microbes are tightly adherent to each other and to an oral substrate by means of an extracellular matrix, i.e., slime layer or glycocalix. ${ }^{18}$ Microbes reproduce at a high rate and they readily adapt physiologically to the environment. ${ }^{12,18,23}$ Established, mature microbes of the extracellular matrix have reduced susceptibility to antimicrobial substances and greater tolerance due to the density and composition. This includes mouthrinses and toothpastes. Chlorhexidine is effective only on the outer layers of plaque biofilm that are within 24-48 hours of formation. $^{18}$

The mechanical disruption of biofilm is necessary to improve periodontal health. Calculus provides an ideal mineralized structure for biofilm formation. The principle, extrinsic etiological aspect was microbial biofilm in chronic periodontitis. ${ }^{18}$ Biofilm can be controlled, but not totally eliminated. Bacteria begin re-colonizing in micrometer grooves and scratches on the tooth surface within 24 hours of disruption. The smooth areas of the tooth show only intermittent areas 
of bacteria. It is important that biofilm be disrupted thoroughly, but carefully to prevent scratches and grooves, which provide a haven for biofilm formation. ${ }^{24}$

\section{Effectiveness}

Baseline indices are recorded prior to treatment, which help to determine the effectiveness of periodontal treatment. Bleeding upon probing (BOP), pocket depth and clinical attachment along with clinical inflammation are the primary indices used. There have been numerous studies showing that ultrasonic periodontal debridement results are comparable to those achieved with manual scaling and root planing with respect to probing depth reduction, gain of clinical attachment and decreased clinical inflammation. Studies recorded initial readings prior to ultrasonic debridement periodontal therapy, manual scaling and root planing, at one week, one month, three months and at six month intervals. BOP sites were significantly reduced at one week with ultrasonic debridement. Reduction in probing depth, increased attachment level and decreased inflammation were also recorded with ultrasonic debridement. Reduction in probing depth at one week is attributed to decreased inflammation and decreased edema. ${ }^{18,26}$ Healing will have occurred by four to six weeks, but tissue repair and collagen replacement will be ongoing for approximately nine additional months. ${ }^{18}$ At six months the indices for ultrasonic periodontal therapy were the similar to those achieved by manual scaling and root planing. ${ }^{13-15,25}$

Studies comparing one time full mouth complete ultrasonic debridement and disinfection with quadrant or sextant manual scaling and root planing over a period of weeks found equal results at six months. ${ }^{4,26-28}$ The strategy of one time full mouth disinfection is to reduce the possibility of the untreated areas re-infecting the treated areas. ${ }^{27}$ Another study published in 1996 by Chapple et al, compared the results of ultrasonic instrumentation operated at full power and at half power. 
There was no significant difference in results in both groups at two weeks, one month, two months, three months and six months. ${ }^{29}$

Ultrasonic debridement and hand scaling acheive equal results. ${ }^{13-15}$ However, ultrasonic debridement accomplishes disinfection without overinstrumentation of the root surface. ${ }^{6,15,25}$ Extensive manual instrumentation to remove calculus deposits results in significant loss of cementum and dentin resulting in dentin sensitivity. ${ }^{30-31}$ Ultrasonic instrumentation requires less chair time for both the patient and the clinician resulting in decreased clinician fatigue. ${ }^{4,14,18,25}$ Hand instrumentation produces a smoother root surface when examined microscopically than ultrasonic instrumentation, but there is no significant clinical difference. ${ }^{25}$

\section{Ultrasonic Scalers}

The magnetostrictive ultrasonic scaler uses flat metal strips stacked together or a metal rod with a variety of working tips. A magnetic field is created when electrical current is transmitted to a wire coil in the handpiece. The magnetic field initiates constriction of the stacks or rod transducer. The alternating current creates an alternating magnetic field, which produces tip vibration. The tips operate between 18,000 and 45,000 cycles per minute. ${ }^{10,32}$ The movement of the tip may be elliptical, circular or almost linear with all surfaces activated allowing for adaptation to the tooth surface using the side, back and front. The action results in producing heat at the tip, which must be cooled. Water is often used as the coolant. Cavitation or bubbles are produced which release energy when they collapse or burst. ${ }^{10-11}$

The piezoelectric ultrasonic scaler vibration occurs when electrical current passes over the surface of crystals inside the handpiece creating a linear movement. The lateral sides of the tip 
are the active portions. The piezoelectric ultrasonic scaler operates between 25,000 and 50,000 cycles per minute. ${ }^{3,5,9-11,33}$

Both magnetostrictive ultrasonic and piezoelectric scalers require water at the tip to reduce frictional heat when the tip contacts the tooth and to maximize cavitational and microstreaming forces. A variety of medicaments can be used in place of water to provide some adjunctive antimicrobial benefit. The medicaments penetrate the new, $24-48$ hour cell layers, but do not penetrate the more established plaque biofilm. ${ }^{18}$ Because of the tight extracellular matrix microbes in biofilms are much more resistant to antimicrobial agents than those dispersed as single cells of the same species. ${ }^{18}$

Ultrasonic scalers provide a mechanical disruption of the plaque biofilm/smear layer. The cavitation produced by the ultrasound vibration of the tips helps to disrupt the biofilm layer of microbes or subgingival bacterial plaque. ${ }^{21-22}$ In the sulcus, the lavage continuously moving over the vibrating tip creates a swirling effect or acoustic turbulence that disrupts the biofilm. The cavitation lavage flushes the debris from the sulcus. The areas reached by the cavitation are detoxified; this reduces periodontal disease causing pathogens. ${ }^{21-22}$

Both magnetostrictive and piezoelectric ultrasonic scalers conserve more of the root structure of the tooth compared to hand scaling. Alterations of the tooth surface are directly related to the amount of pressure applied by an instrument. Ultrasonic scaling requires less pressure to accomplish removal of calculus, endotoxins and biofilm. ${ }^{6-7}$ The 1990s produced research which recognized that cementum removal was not necessary for treatment of periodontal disease. ${ }^{6}$ Thorough removal of calculus is required for periodontal scaling and root planning, however over instrumentation resulting in significant cementum removal is not the goal of periodontal 
therapy. ${ }^{11}$ Ultrasonic scalers cause less tissue trauma resulting in quicker healing and greater patient comfort. ${ }^{34}$

\section{Ultrasonic tips and inserts}

The original ultrasonic scalers were designed to dislodge calculus deposits supragingivally. The large, bulky tips were designed for removal of supragingival calculus and stain. The position of the water port necessary to cool the magnetostrictive tips created excessive aerosol, which obscured vision of the working area. This resulted in water running down the patient's neck, an aerosol spray produced over their face and a great amount of bacteria-laden aerosol introduced into the air, creating a biohazard. ${ }^{35}$ Patient comfort was compromised.

As the understanding of periodontal disease has increased, advancements have been made in ultrasonic technology. In the 1980s, manufacturers designed slim diameter, longer tips that can reach deeper into the subgingival sulcus and access the narrow space between the tooth and the soft tissue. The slim diameter tips are smaller than curet blades. ${ }^{17}$ The new thin micro-ultrasonic tips access the deep and narrow defects and class II and class III furcation areas much easier than even the mini thin long curets. ${ }^{36}$ The tip of the curet is often wider than the furcation area. The periodontal ultrasonic inserts are good for accessing deep defects and furcation areas. They have been shown to penetrate the pocket approximately one millimeter farther than traditional hand instruments. ${ }^{37}$

There are more than fifty ultrasonic tips and inserts available from a variety of manufacturers. They are designed to work in specific areas and for specific needs. A heavy tip is appropriate for heavy calculus especially supragingivally. For heavy subgingival calculus, the tip needs to be able to provide enough vibration when used on medium high-to-high power to fracture the 
calculus. A standard diameter tip would be used for general debridement or moderate to heavy supragingival and subgingival calculus. An insert design for subgingival periodontal debridement has a tip that is $40-47 \%$ thinner than the standard diameter tip with a longer shank and can reach much further into subgingival areas, furcations, root concavities and interproximal areas. Less power is needed as the tip diameter becomes smaller. The fine thin tips should be used only on low to medium power. If not used properly, an ultrasonic tip used on low power can burnish rather than remove the calculus. ${ }^{7}$ One study found more cavitation occurred with broader tips at the same power setting than the slimmer tips. This study suggests that the current drive towards slimmer tips may enable deeper pocket cleaning, but resulting in less biophysical benefits. ${ }^{4}$

Specialized tips are available. A beavertail tip has a wide working end ideal for removing thick tobacco stains, orthodontic cement, tenacious calculus, and for heavy deposits. Special carbon composite, plastic, silicon or resin tips are available for use around implants and cosmetic restorations that will not damage the materials. Site-specific inserts and tips can have a right or left curved shank or a shank with a number of backbends, all designed to enhance adaptability to the root anatomy of the teeth. A recent option for ultrasonic scaler tips is the addition of fiber optics or an (light emitting diode) LED light, to illuminate the working area. ${ }^{38}$

Tips should be evaluated regularly for wear. Most manufacturers supply a wear guide to measure the wear of the tip. As a tip wears, effectiveness is reduced. One millimeter of tip wear results in approximately $25 \%$ loss of efficiency. Two millimeters of wear results in approximately $50 \%$ loss of efficiency, and should be replaced. ${ }^{5,38}$ One manufacturer has produced a coated ultrasonic scaler tip. New tips appear gold and the color fades with use, resulting in a more obvious sign of wear. ${ }^{9}$ 
Ultrasonic scaling instruments can be very effective with proper and deliberate, multidirectional strokes, keeping the tip constantly moving. The entire surface of the tooth and root must be contacted by the tip using short and overlapping strokes, vertical strokes, horizontal strokes, oblique or cross-hatching strokes and circumferential strokes for effective removal of biofilm pathogens. Fracturing of calculus can be done from the top of the deposit, gently tapping the deposit using the active sides of the tip or insert, unlike curets, which require the clinician to place the instrument under the deposit. The point of the tip can damage the cementum and dentin, therefore, clinicians need to be aware of the active area of the tip and tooth morphology for proper adaption of the tip to the tooth. The angulation of the tip should be close to 0 degrees, but no more than 15 degrees. The lateral pressure should be lighter than that used with a hand instrument. Increased pressure decreases the effectiveness of the tip by restricting or stopping the movement of the tip. ${ }^{7}$

\section{Medicaments}

Some ultrasonic units have self-contained reservoirs that are not connected to the main water supply of the operatory. This allows for the use of antimicrobial medicaments for lavage with the purpose of reducing microorganisms through cell death. Chlorhexidine gluconate, brand names Peridex ${ }^{\circledR}$ and PeriGard $\AA$, is effective against both gram-negative, gram-positive, aerobes and anaerobes microorganisms. It is available by prescription or through a dental office. It is also available with or without alcohol with no sustained difference in bactericidal effectiveness. ${ }^{9}$ Chlorhexidine gluconate exposure results in lysis of the cell wall resulting in cell death. It binds to salivary mucins, which reduces the formation of plaque, reducing attachment to the tooth. It penetrates existing biofilm, killing the microorganisms within the top layers. Chlorhexidine

binds to the soft tissues of the mouth and continues to be released for up to 12 hours. ${ }^{12,18,32}$ 
Cetylpyridinium chloride, brand names Crest ${ }^{\circledR}$ Pro-Health ${ }^{\mathrm{TM}}$ and BreathR ${ }^{\circledR}$, is a quaternary ammonium compound that results in cell lysis and cell death. It binds with the tooth structure and the biofilm but is released more quickly; therefore, the effects are not as long lasting as chlorhexidine. $^{32}$

Phenolic essential oils, brand name Listerine ${ }^{\circledR}$, work by denaturating the proteins of the cells resulting in cell lysis and cell death. It changes the enzyme activity and has some antiinflammatory action. Other liquids used are sterile saline, stannous fluoride and povidone iodine. . $^{3,5,26}$

\section{Infection control}

Ultrasonic scalers produce bacteria-laden aerosol into the air creating a biohazard that remains in the air for at least 30 minutes and up to 24 hours. ${ }^{35,40}$ The area of exposure can be up to 20 feet from the treatment center. ${ }^{33}$ Having the patient rinse with an antimicrobial mouthrinse prior to treatment will decrease the amount of bacteria in the mouth to be released into the air. $^{35,40}$ Some studies show that two-30 second rinses decreased more bacteria for a longer period of time than a single 30 second rinse. ${ }^{41}$ High-speed evacuation is recommended to capture the excess water to decrease the amount of bacteria-laden aerosol released into the air. $^{35,42-43}$ High-speed evacuation can significantly reduce the aerosol released into the surrounding air. ${ }^{33,41,43}$ Studies have shown that blood is in the aerosols from ultrasonic scalers even though not visible. ${ }^{35,41}$ Reducing the water flow decreases the amount of aerosol released into the air. One advantage of the piezoelectric ultrasonic scaler is that because the tip does not generate much heat, less water is needed to cool the tip. ${ }^{10,12,40,43}$ Proper infection control of the bacteria laden aerosol is necessary when using ultrasonic scalers. $4,11,35,41,43$ 


\section{Contraindications for Use of Ultrasonic Scaler}

The use of an ultrasonic scaler is contraindicated for use in patients with communicable diseases, such as active tuberculosis, hepatitis, HIV, etc., that might be transmitted through contaminated aerosol. Patients with respiratory issues including severe asthma, emphysema, cystic fibrosis and chronic pulmonary disease are at risk of inhaling bacteria-laden aerosol, which could be aspirated into the lungs resulting in pulmonary infection. ${ }^{44}$

Historically, cardiac pacemakers have been considered a contraindication for the use of ultrasonic scalers. Unshielded cardiac pacemakers were made and implanted in the 1960s and 1970s. According to the predominant manufacturers of pacemakers in the United States, (St. Jude Medical, Inc., Medtronic, Inc. and Boston Scientific), these devices are shielded therefore the magnetostrictive ultrasonic electromagnetic field will not create interference and the use of a magnetostrictive ultrasonic scaler poses no risk to a patient with a cardiac pacemaker. ${ }^{45-47}$ The piezoelectric ultrasonic scaler does not produce an electromagnetic field therefore, it does not posed a risk to patients with cardiac pacemakers. A review of scientific literature finds conflicting studies regarding the risk of using a magnetostrictive ultrasonic scaler on a patient with a pacemaker. The American Academy of Periodontology 2000 position paper recommends not using the magnetostrictive ultrasonic scaler on a patient with a pacemaker. ${ }^{3}$ An in vitro study in 1998 by Miller et al reported interference by the magnetostrictive ultrasonic scaler. ${ }^{48}$ A 2005 in vivo test by Patel et al and a 2007 study by Brand et al found no interference with a pacemaker by the magnetostrictive ultrasonic scaler. ${ }^{49-50}$ Roedig et al in the June 2010 Journal of the American Dental Association concluded that it is necessary to be cautious in using magnetostrictive ultrasonic scalers on patients with pacemakers. ${ }^{51}$ 


\section{Chapter 3}

\section{Methods}

\section{Participants}

The population for this study consisted of the directors of the 323 accredited dental hygiene programs in the United States. The names and email addresses were obtained from the American Dental Hygienist Association's website. Demographically, the programs were divided into four regions, Northeast, South, Midwest and West, using a regional designation employed by the United States Census.

\section{Study Design}

This is a descriptive educational research study involving a survey. The West Virginia University Institutional Review Board for Protection of Human Subjects granted exempt status on May 25, 2011 for the survey to be conducted (Appendix A).

\section{Instrument}

The survey was comprised of 64 questions. (Appendix B) The survey was categorized into three sections, demographics, curriculum and equipment. Question eight in the demographic section asked if the program had an onsite clinical teaching facility for students, if the participant answered no, then the participant was not eligible to complete the survey. Questions included multiple choice and open-ended unstructured responses. Many questions included the choice of other, followed by a question with a text box for the participant to add more information. In the curriculum portion, participants were asked when answering the questions, to assume that the clinical portion of dental hygiene education occurred over two years. The final question asked what new technology was available to the students. A list was provided along with a text box for participants to list additional technology obtainable by their students. 


\section{Procedure}

An email was sent to each director of the 323 accredited dental hygiene programs in the United States requesting that they participate in this research project survey. (Appendix C) The email contained the title of the research project and a link to the cover letter on the (Secure Online Environment) SOLE web page. (Appendix D) At the bottom of the cover letter, the participant clicked on the agreement to participate box, which connected them to the survey. After clicking the box, the participant would be able to access the survey. The cover letter stated

that participation was voluntary, the responses would be confidential, and collected in aggregate. An email reminding participants to complete the survey was sent five days later (Appendix E). The email contained all the original information so the participant would not need to search for the previous email.

A third email was sent sixteen days after the first email and contained all the original information (Appendix F). This email extended the participation deadline ten days after the first deadline. However, the survey remained open for a month after the deadline.

The reasons for the short deadline and reminders were to try to gain participation before directors finished for the summer, some directors would be attending the American Dental Education Allied Program Directors' Conference and some directors might be attending the American Dental Hygienists' Association meeting; all of which occurred the first couple of weeks in June.

\section{Statistical Analysis}

At the completion of the open survey, results were transferred to an Excel spreadsheet, which was utilized to conduct statistical analysis. Statistical treatment included frequencies, cumulative 
frequencies, percentages and Chi square analysis. Results were reported using table and histogram figures. 


\section{Chapter 4}

\section{Results}

Three hundred and twenty three program directors were sent emails inviting them to participate in the survey. Eleven email addresses were no longer in use, one program's email address could not be obtained, four automated messages were received stating that the directors were out of the office for the summer, two directors responded stating that they do not answer surveys and one director wrote that the program was too new to answer the questions, reducing the number of possible participants to $n=304$. Three more programs were eliminated from the total population due to not having an onsite clinical teaching facility reducing the final number to 301 participants. The total response rate was $45 \%(n=136)$. The greatest responses came from programs located in the south (35\%) and the midwest (38\%) regions. (Figure 1.)

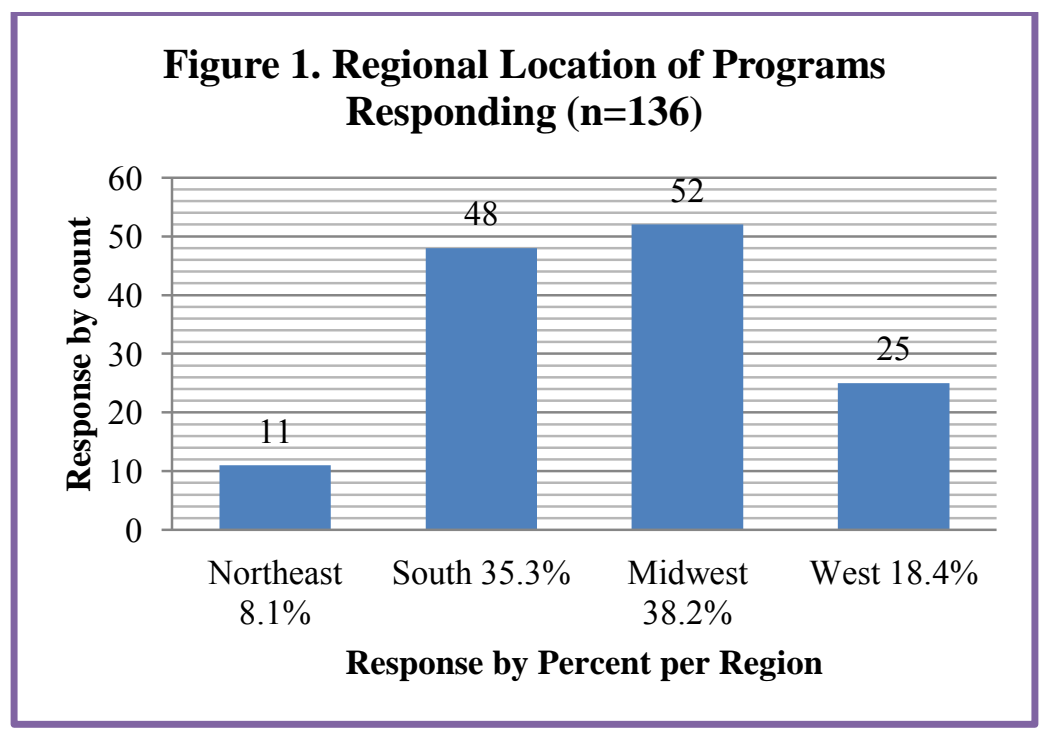

Northeast-Maine, New Hampshire, Vermont, Massachusetts, Rhode Island, Connecticut, New Jersey, New York, Pennsylvania.

South-West Virginia, Virginia, Maryland, Delaware, Kentucky, Tennessee, Georgia, Alabama, Arkansas, Oklahoma, Mississippi, Florida, Louisiana, Texas, Washington, D. C. 
Midwest- Iowa, North Dakota, Minnesota, Wisconsin, Michigan, Ohio, Indiana, Illinois, Missouri, Kansas, Nebraska.

West-Montana, Wyoming, Colorado, New Mexico, Arizona, Idaho, Utah, Washington, Oregon, Nevada, California, Alaska, Hawaii.

\section{Demographics}

The degree most frequently conferred by respondents is the associate degree $(80 \%)$. Thirty programs offer a bachelor's degree and ten offer a master's degree. (Table 1.) Other degrees conferred are an Associate in Health Science, Associate in Specialized Technology, a Bachelor's degree in Public Health Dental Hygiene, degree completion, Master's of Science in Human Services-Gerontology, Graduate Certification-Clinical Counseling, and a Master's in Higher Education. Most programs (86\%) are divided into semesters with 12 programs divided into quarters. The majority of programs responding require the equivalent of at least six semesters for completion of an associate degree with some requiring pre-requisite courses prior to entering the program. Eighty-nine (65\%) of all programs require summer sessions with the majority (77\%) requiring one summer session and $21 \%$ requiring two summer sessions. One program located in the south conferring an associate degree, requires three summer sessions. Seventeen $(13.7 \%)$ dental hygiene programs responding were associated with dental schools. Forty-seven of the 136 responses reported no summer session required.

\begin{tabular}{|l|r|r|}
\hline \multicolumn{3}{|l|}{ Table 1. $(\mathbf{n}=136)$} \\
\hline Degree Conferred by Dental Hygiene Programs \\
\hline & $\begin{array}{l}\text { Responses } \\
\text { per Degree }\end{array}$ & $\begin{array}{l}\text { Percentage } \\
\text { of Responses }\end{array}$ \\
\hline AS/AA/AAS & 110 & $80 \%$ \\
\hline Certificate/Diploma & 5 & $3.60 \%$ \\
\hline BS in Dental Hygiene & 30 & $21.90 \%$ \\
\hline MS in Dental Hygiene & 10 & $7.30 \%$ \\
\hline Other & 5 & $3.60 \%$ \\
\hline
\end{tabular}




\section{Curriculum}

An equal number of dental hygiene programs (22\%) introduce ultrasonic scaling theory in the first term and the third term of the program. Most students (67\%) are introduced to ultrasonic scaling theory during the second term of the program.

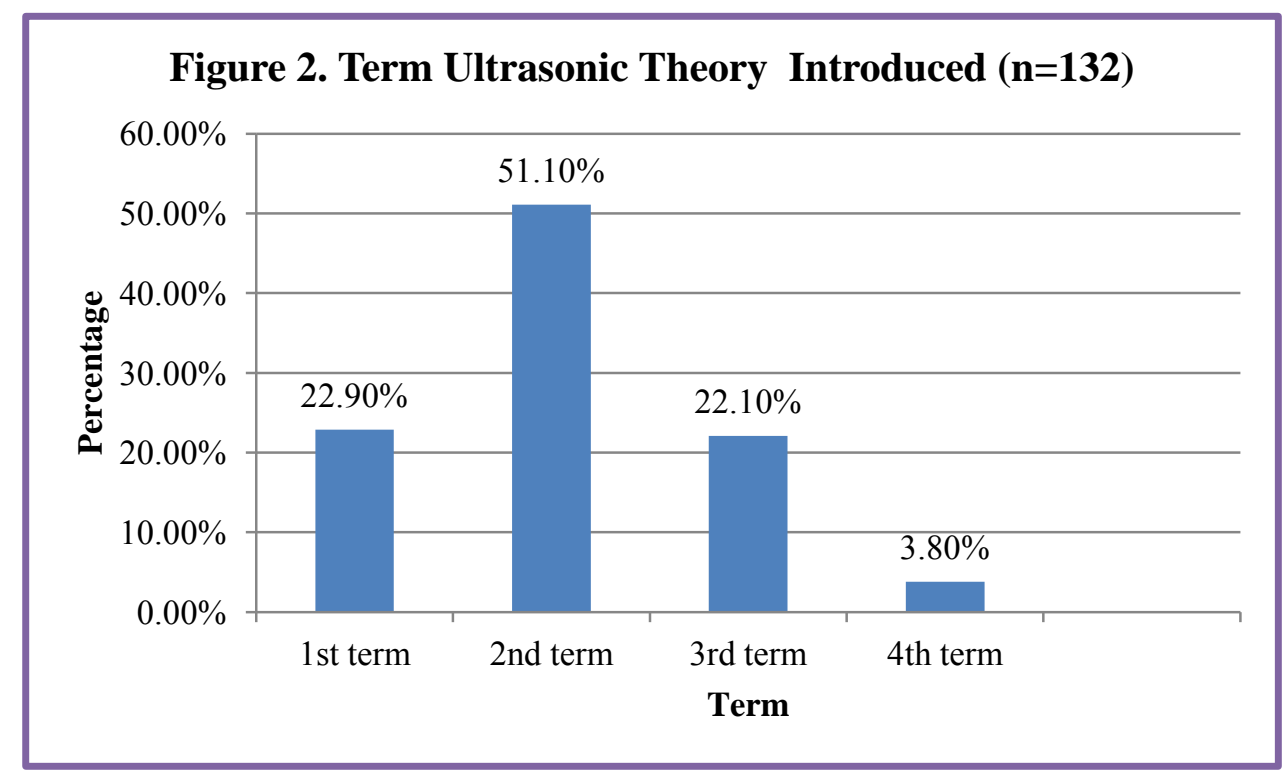

Those programs responding utilize three primary textbooks for the instruction of ultrasonic scaling. The most commonly used textbook is Fundamentals of Periodontal Instrumentation by Nield-Gehrig. The second most commonly used textbook is Clinical Practice of the Dental Hygienist by Wilkins. Many programs use both textbooks. The third textbook was Dental Hygiene Theory and Practice by Darby and Walsh. (Figure 2.) One hundred and seven programs include ultrasonic scaling instruction in courses addressing periodontics, clinical seminars, theory, practice management, pain management, oral therapy. Many respondents indicated that ultrasonic scaling instruction was included in most courses. 


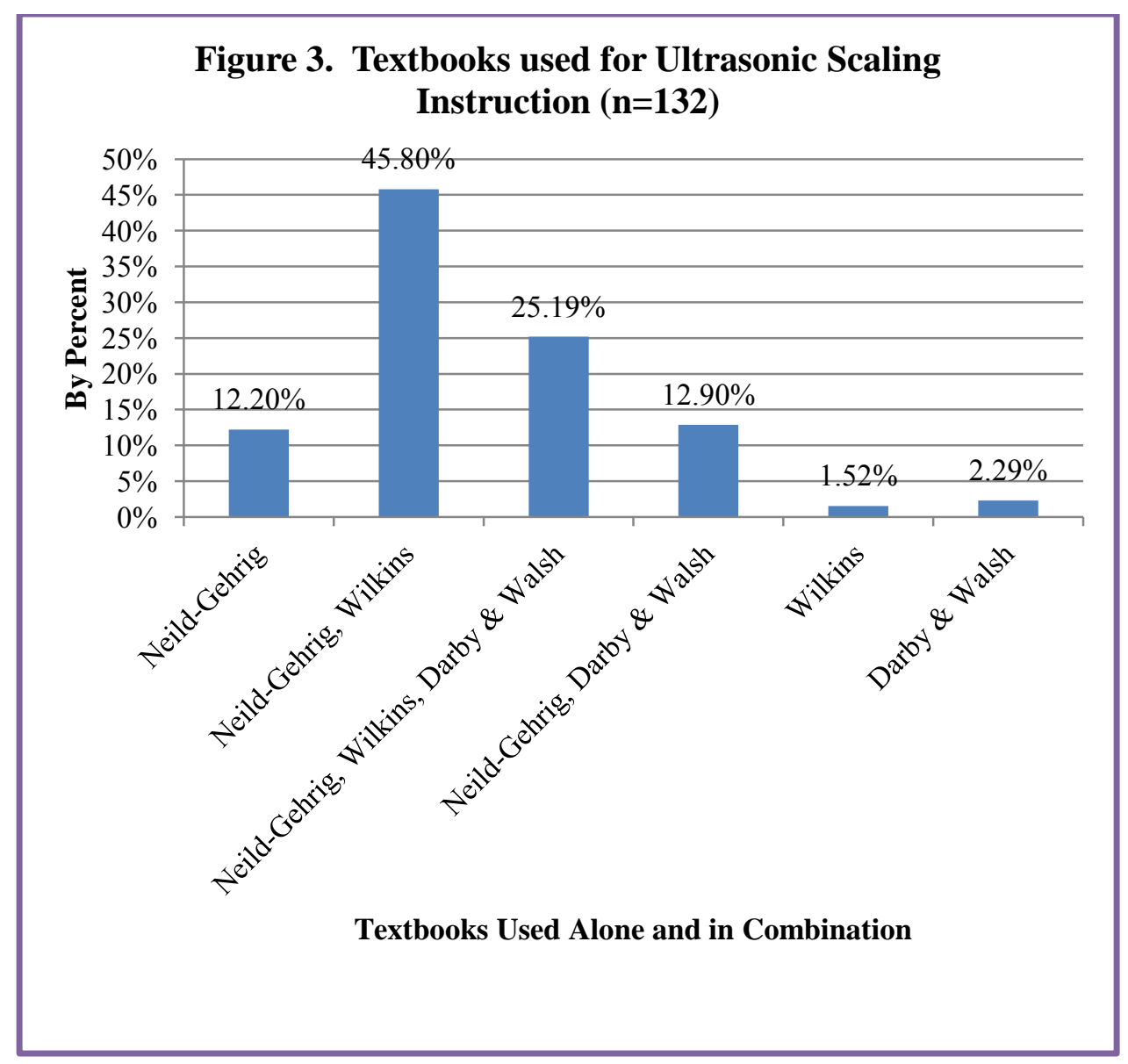

Eighty-six percent of dental hygiene programs begin pre-clinical instrumentation in the first term of the program, but most (74\%) do not include ultrasonic scaling instruction during the preclinical instrumentation course. The majority (89.23\%) of programs responding introduce hand scaling instrumentation instruction prior to the introduction of ultrasonic scaling instrumentation instruction. (Figure 3.) Seven programs introduce both hand scaling and ultrasonic scaling instrumentation instruction concurrently. Respondents (68.7\%) reported that equal emphasis is placed on hand scaling instrumentation and ultrasonic scaling instrumentation. (Figure 4.) 

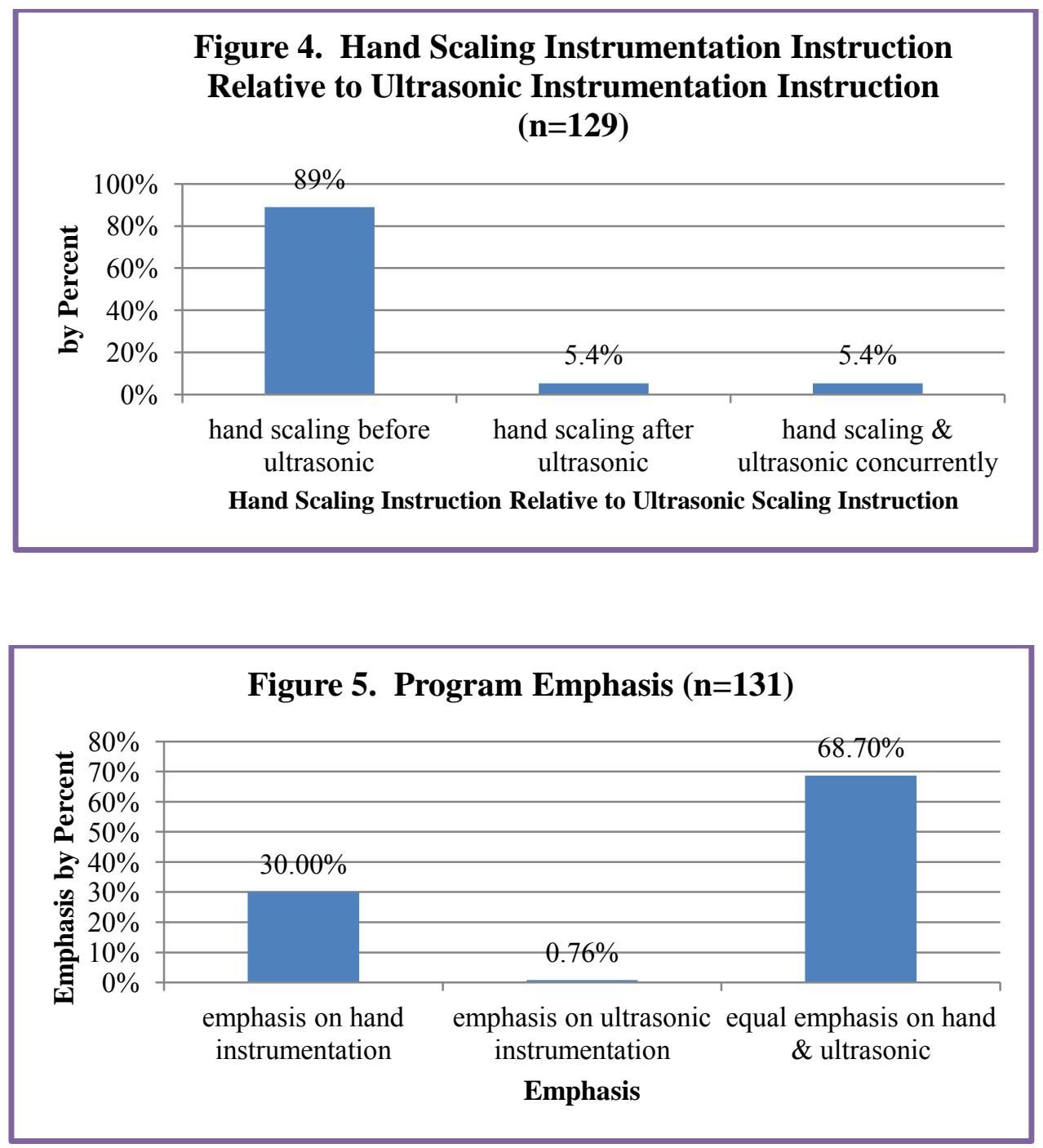

This study was limited to programs that had onsite clinical facilities for students to treat patients. The academic term in which students had actual application of ultrasonic scalers for patient treatment varied with most having patient application in the third term. (Figure 5.)

Criteria for choosing to use an ultrasonic scaler varied. The respondent could choose all answers that applied. (Figure 6.) Many respondents commented that their students are encouraged to use the ultrasonic scaler for all patients even if no calculus is visible. Other respondents stated the ultrasonic scaler is utilized to flush out the sulcus and reduce biofilm or microbial load benefiting most patient profiles. More than one answer could be selected therefore answers will not equal $100 \%$. 
Figure 6. Criteria for Use of Ultrasonic Scaler $(n=132)$

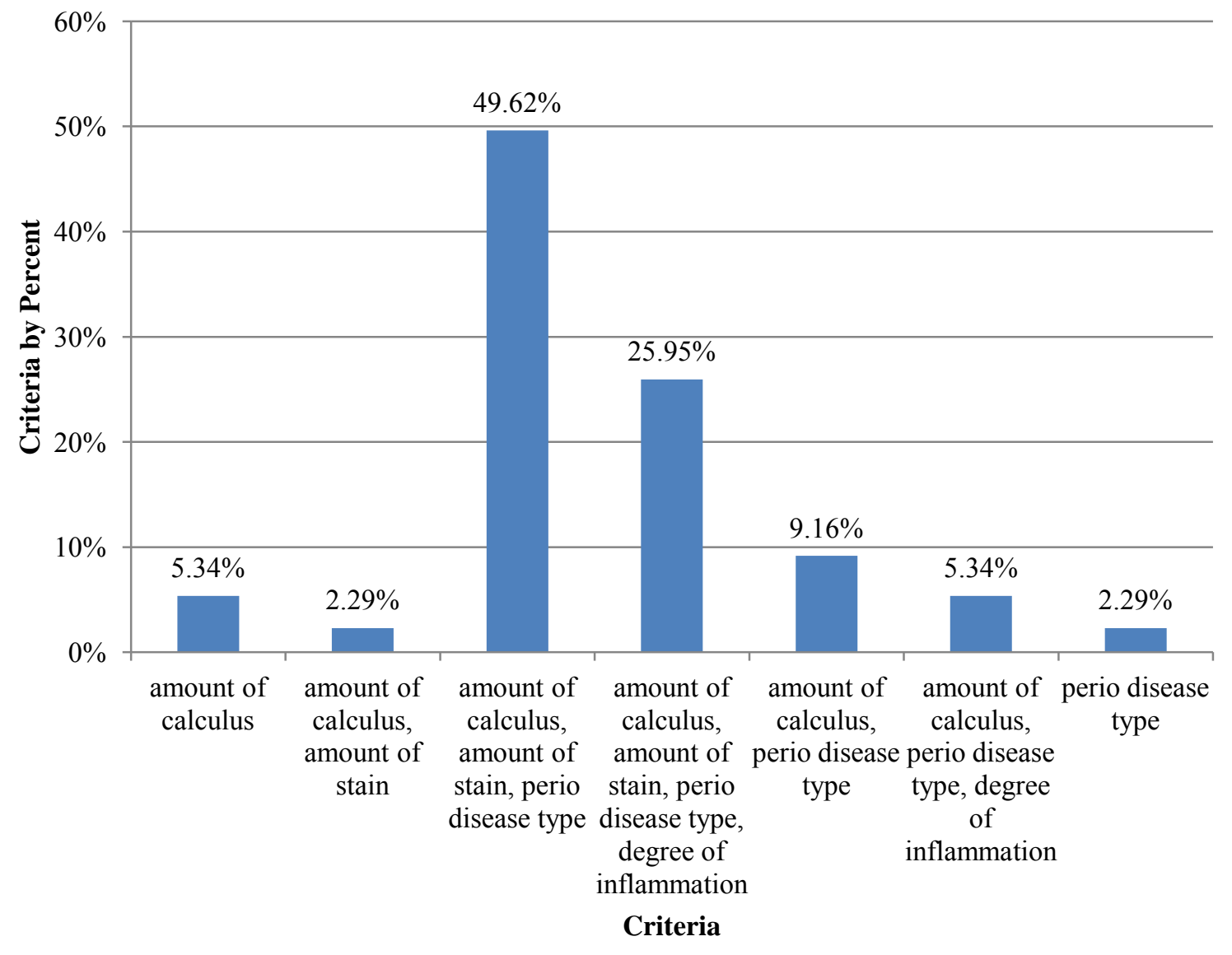

Each possible criterion for choosing to use the ultrasonic scaler was further developed to determine how each program responding defined the amount of calculus, the amount of stain, the amount of periodontal disease. More than one answer could be selected therefore responses do not equal 100\%. (Figures 6a, 6b, 6c.) 


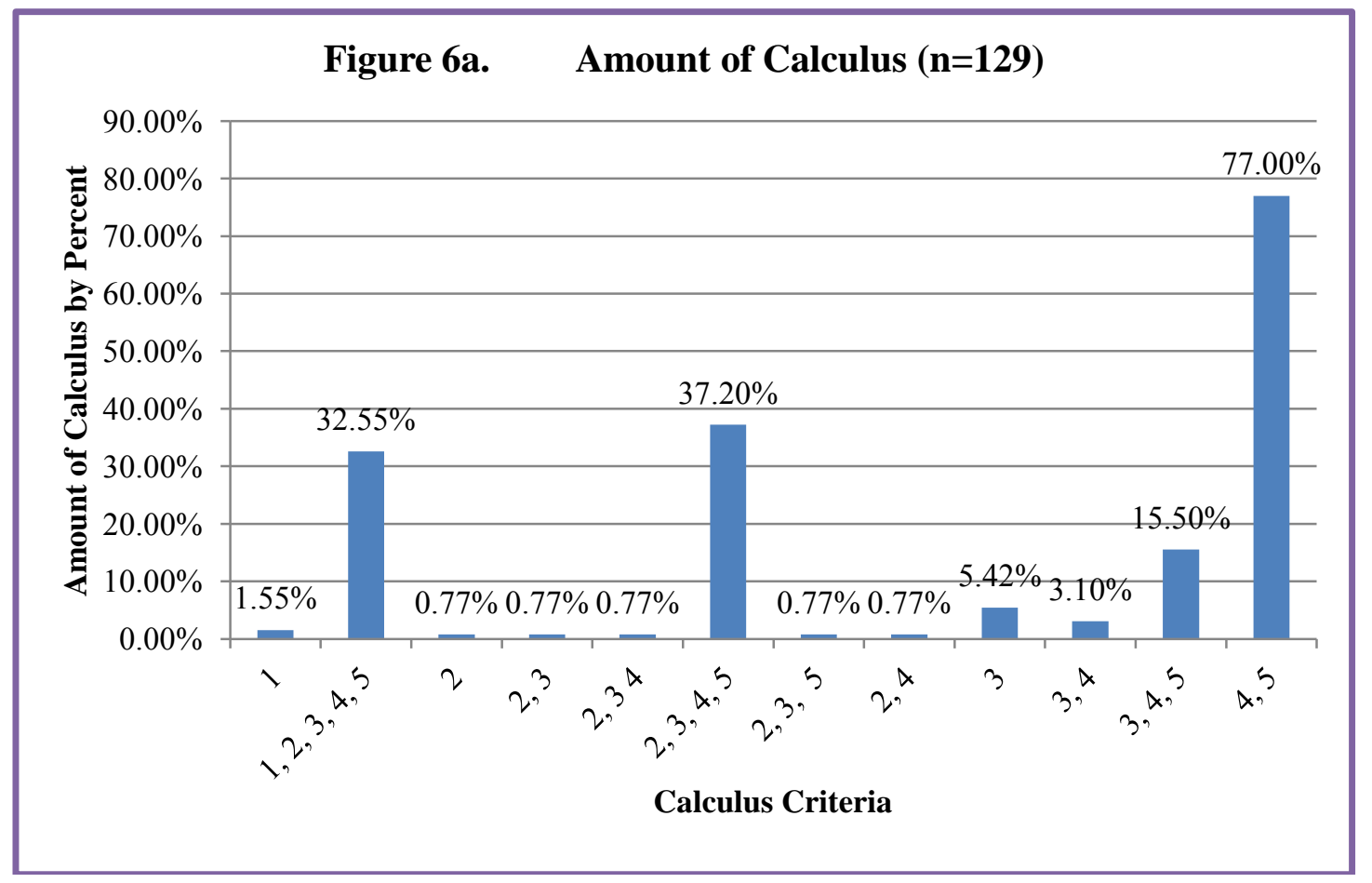

1 - very light calculus, no sub gingival

2 - light supragingival calculus 1-2 mm wide, sheet calculus, subgingival calculus 1-2 mm into sulcus 3 - supragingival tenacious calculus, black tenacious calculus on at least 3 teeth, extending $5+\mathrm{mm}$ 4 - root debridement, 3-5 mm subgingivally

5 - root debridement greater than $5 \mathrm{~mm}$ subgingivally

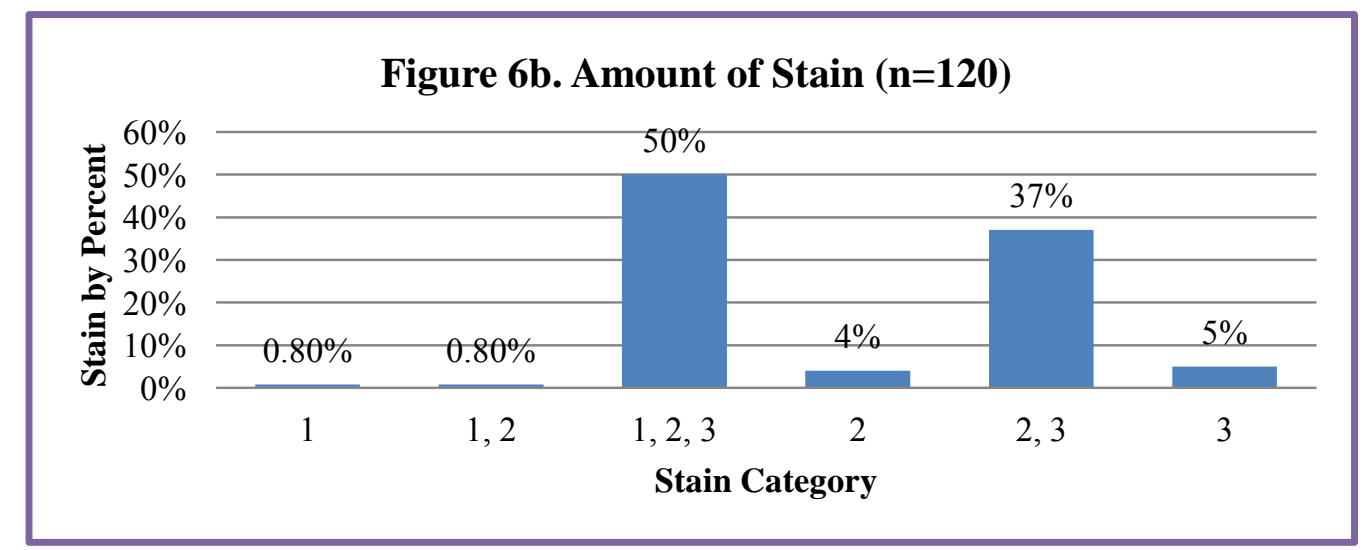

1 - light localized or generalized stain

2 - medium (dark stain covering less than $1 / 3$ of clinical crown)

3 - heavy, dark leathery black/brown stain covering more than $1 / 3$ of clinical crown 


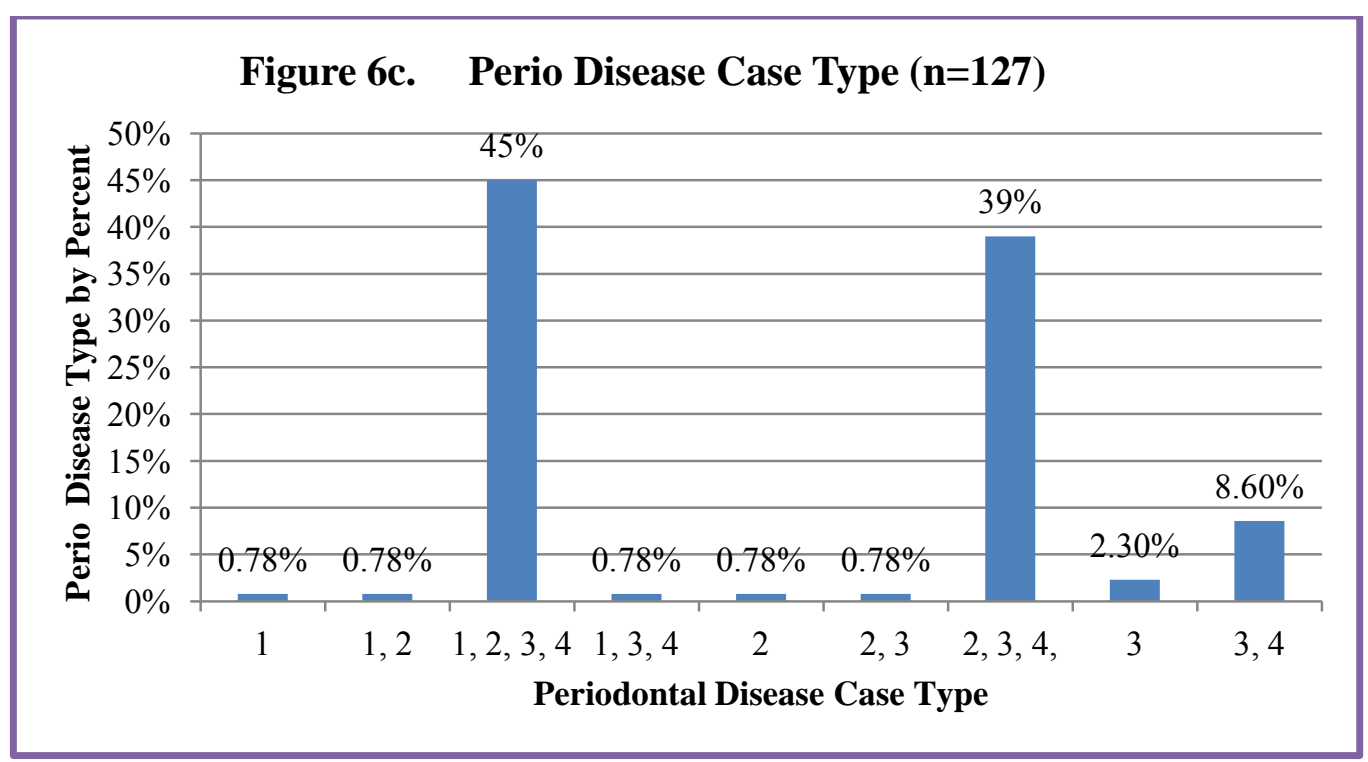

1 - ADA Periodontal disease case Type I - Gingivitis-Clinical evidence of inflammation but no bone loss or apical migration of epithelial attachment.

2 - ADA Periodontal disease case Type II - Early Periodontitis-Slight crestal bone loss and minimal to moderate pocket depths $(4-5 \mathrm{~mm})$.

3 - ADA Periodontal disease case Type III - Moderate Periodontitis-Moderate to deep pockets (6 mm) and moderate bone loss (up to 1/3).

4 - ADA Periodontal disease case Type IV - Advanced Periodontitis-Bone loss greater than 1/3 with deep pockets (deeper than $6 \mathrm{~mm}$ ) and often furcation involvements.

Respondents choosing inflammation as a criterion for using the ultrasonic scaler were asked to explain. Forty-six respondents explained their choice. Answers included any level of inflammation including early gingivitis, (necrotizing ulcerative gingivitis) NUG, bleeding upon probing, attachment loss and most patients benefit from the lavage to reduce biofilms. One respondent stated that their program had "shifted the emphasis to ultrasonic instrumentation...focusing on biofilm rather than only hard deposits." Another answered that students used "evidence based decision making..." for using the ultrasonic scaler. One respondent 
stated that ultrasonic scaling instrumentation was introduced in the second semester of the first year because they wanted students to "provide ethical treatment." They noted that many students "...do not have strong pressure on their fulcrum for advanced scaling techniques. The ultrasonic helps them adapt properly to the tooth...They are less afraid to enter the pocket with a non-sharp instrument...The students feel the process is beneficial."

Most programs (56\%) do not have a minimum requirement for use of the magnetostrictive ultrasonic scaler. Of those programs that do have a minimum requirement, six stated that the magnetostrictive scaler is used on almost every patient. Minimum requirements ranged from two quadrants to sixteen uses. The most common answer was a minimum of two uses per term. Many required students to demonstrate competency on patients with light, moderate and heavy calculus using a check off list for skill evaluation.

The piezoelectric ultrasonic scaler requirement ranged from two quadrants to four utilizations. Most programs do not have a minimum requirement. Most programs do not have piezoelectric ultrasonic scalers. Five respondents stated that a piezoelectric ultrasonic scaler is available for "enrichment" or for the students to "experience."

Teaching strategies were explored and respondents could choose all answers that applied. (Figure 7.) The most common strategy was onsite clinical patients with 117 marking this answer and 110 also marking student partners. More than one answer could be selected therefore totals do not equal $100 \%$. 
Figure 7. Teaching Strategies Used for Ultrasonic Instrumentation

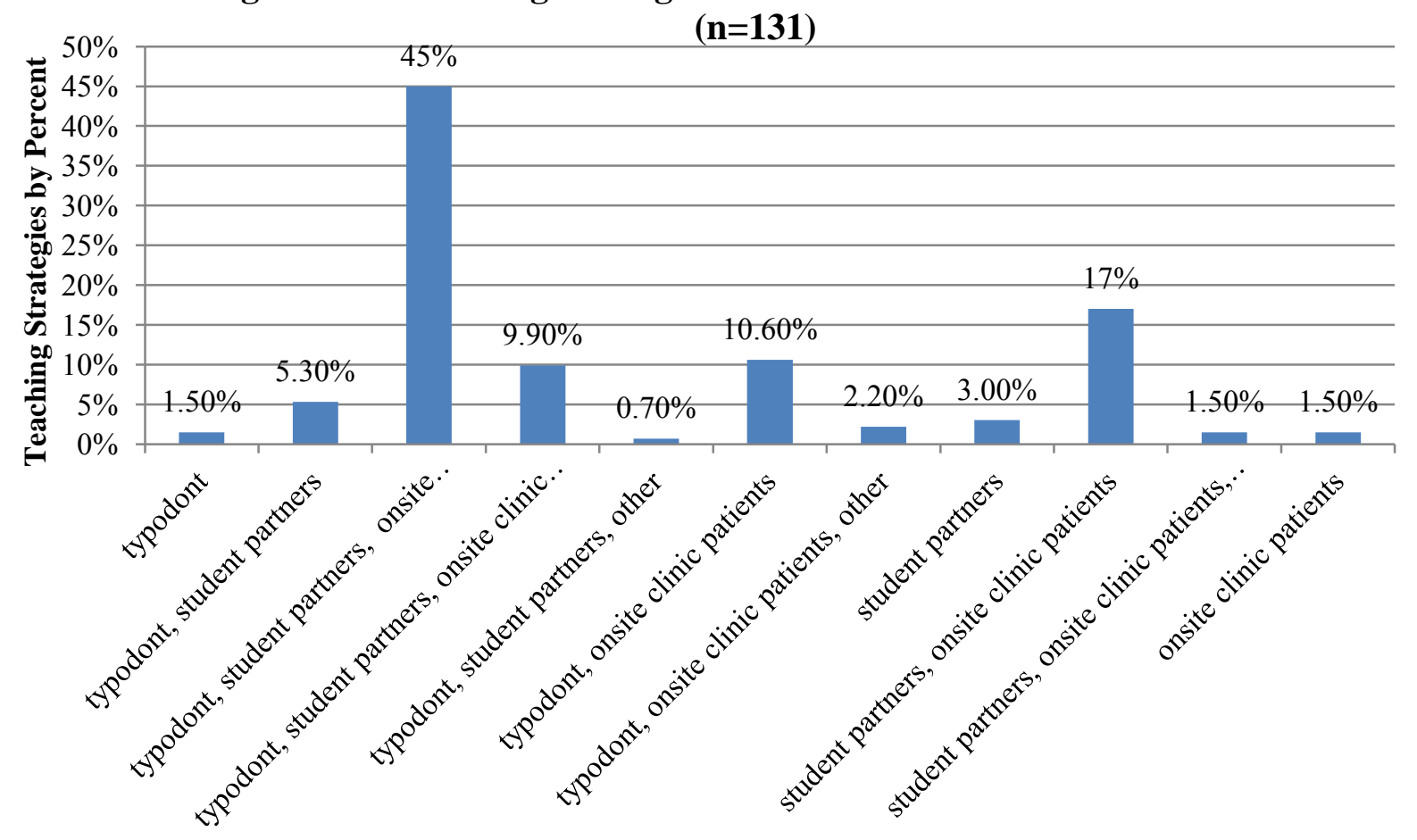

Strategies Used for Teaching

Those marking other were asked to elaborate on the teaching strategies. Case based and evidence based learning were mentioned. Speakers from ultrasonic companies provided presentations to the students. Teeth painted with nail polish set in plaster along with striped birthday candles were used so students could visualized the working surface, strokes and pressure required to remove the coloration. Teeth with simulated calculus were also used. Many used videos and You Tube along with classroom instruction. Students in one program use a hotdog to visualize the effect of the ultrasonic scaler on soft tissue.

One respondent outlined a lab series that included six stations. At the first station students identify tips and used the tip on a typodont painted with nail polish. Station two demonstrates the 
power of the ultrasonic tip by piercing a hole in an aluminum can. Station three is adaptation of the tip on a penny. Station four is a root planing insert demonstration, discussion to prevent tip damage and the use of a wear guide. Station five teaches water and power settings and lavage versus optimal spray. Station six methods of cord management are explored.

The survey asked about ultrasonic tip adaptation techniques taught in the program. Four choices were provided in addition to the choice of "Other." A text box was provided for respondents to write other adaptation techniques not listed. (Figure 8.) Other techniques mentioned were multidirectional, handle parallel to occlusal plane, and chiseling. One comment stated that they do not teach the use of the "face (inside curve), because they have seen too many broken tips."

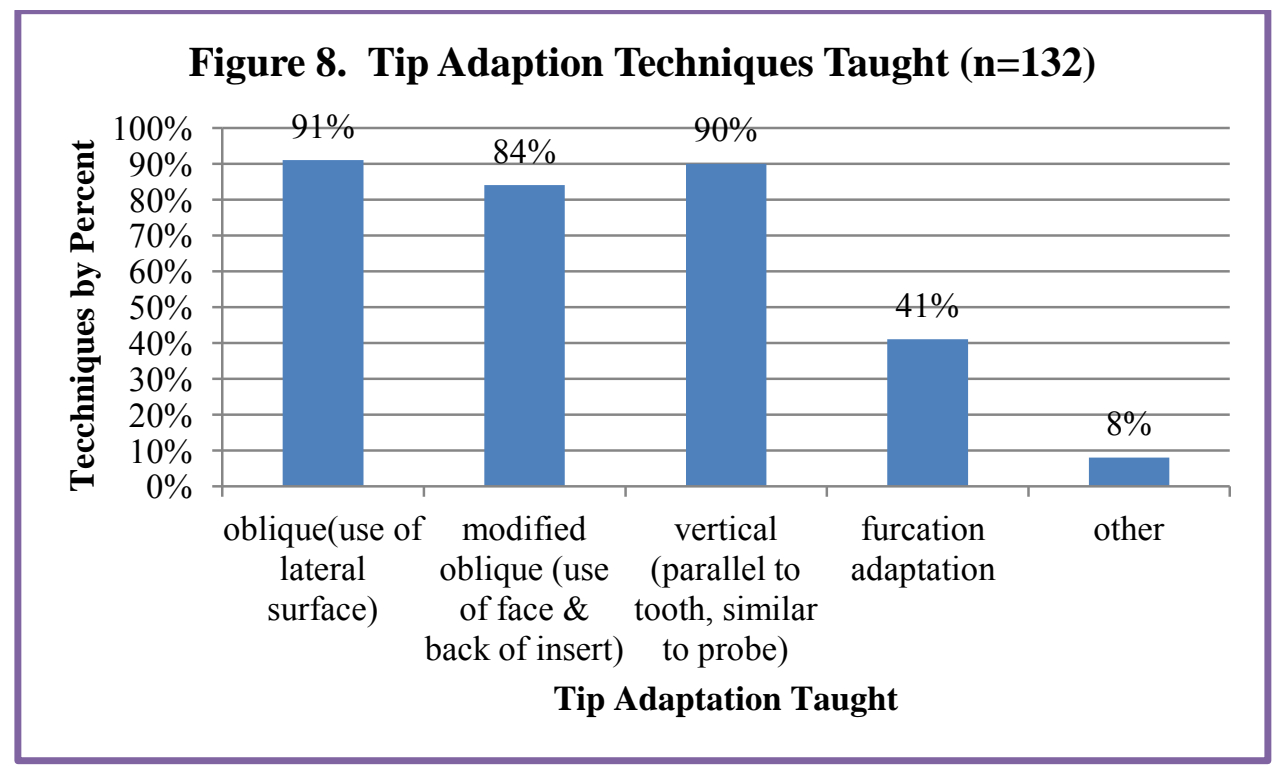

The survey asked about ultrasonic scaling strokes taught to students. There was general agreement with teaching horizontal, oblique and vertical scaling strokes. (Figure 9.) Other stokes mentioned were circumferential, modified oblique, overlapping, sweeping, and furcation angulation. Since more than one answer could be selected, the responses do not equal 100\%. 


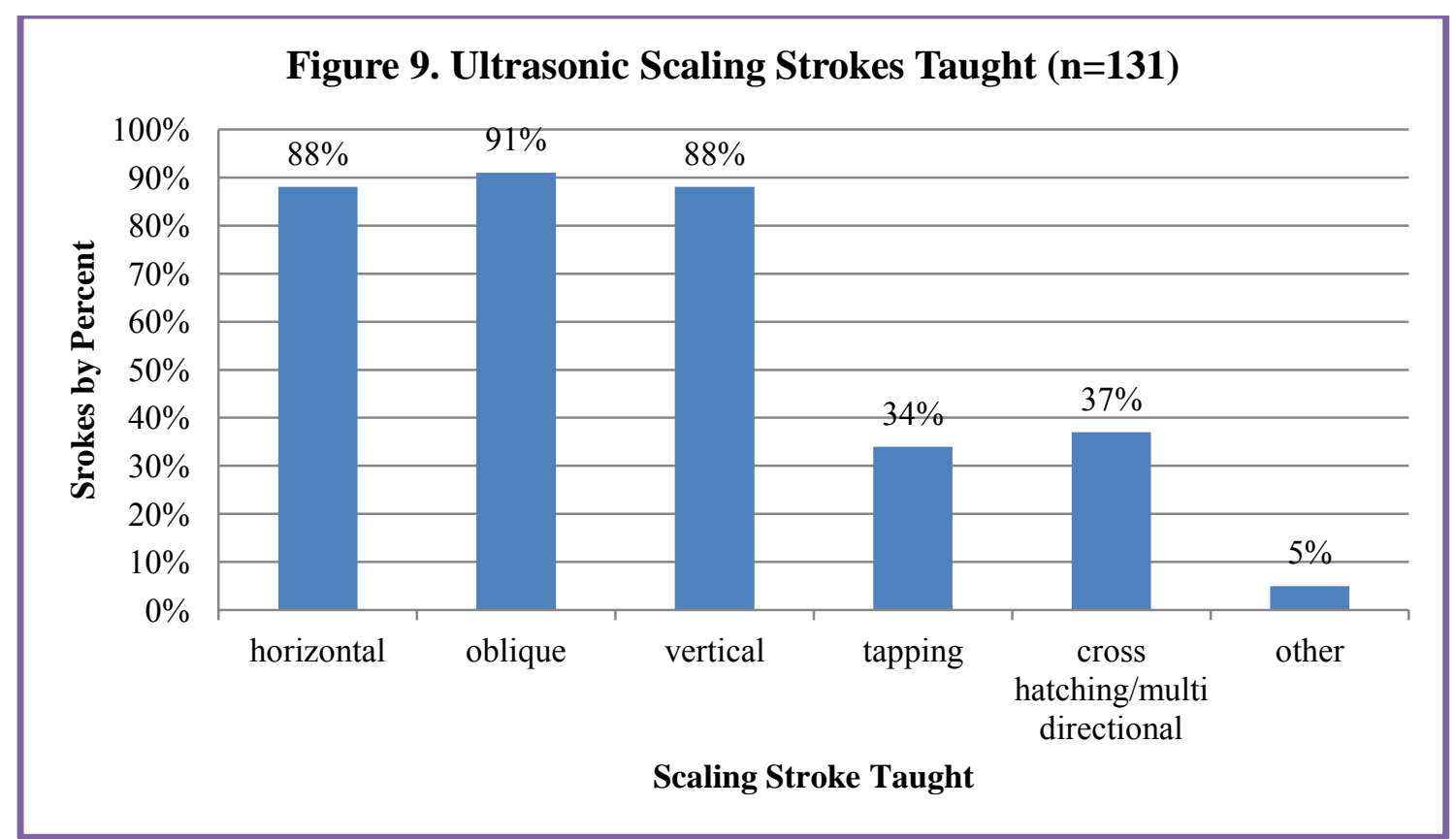

The use of an ultrasonic scaler is contraindicated for several reasons. Survey participants were asked to check all answers that applied to instruction in their program. The most universally taught contraindication was a patient with respiratory risk. (Figure 10.)

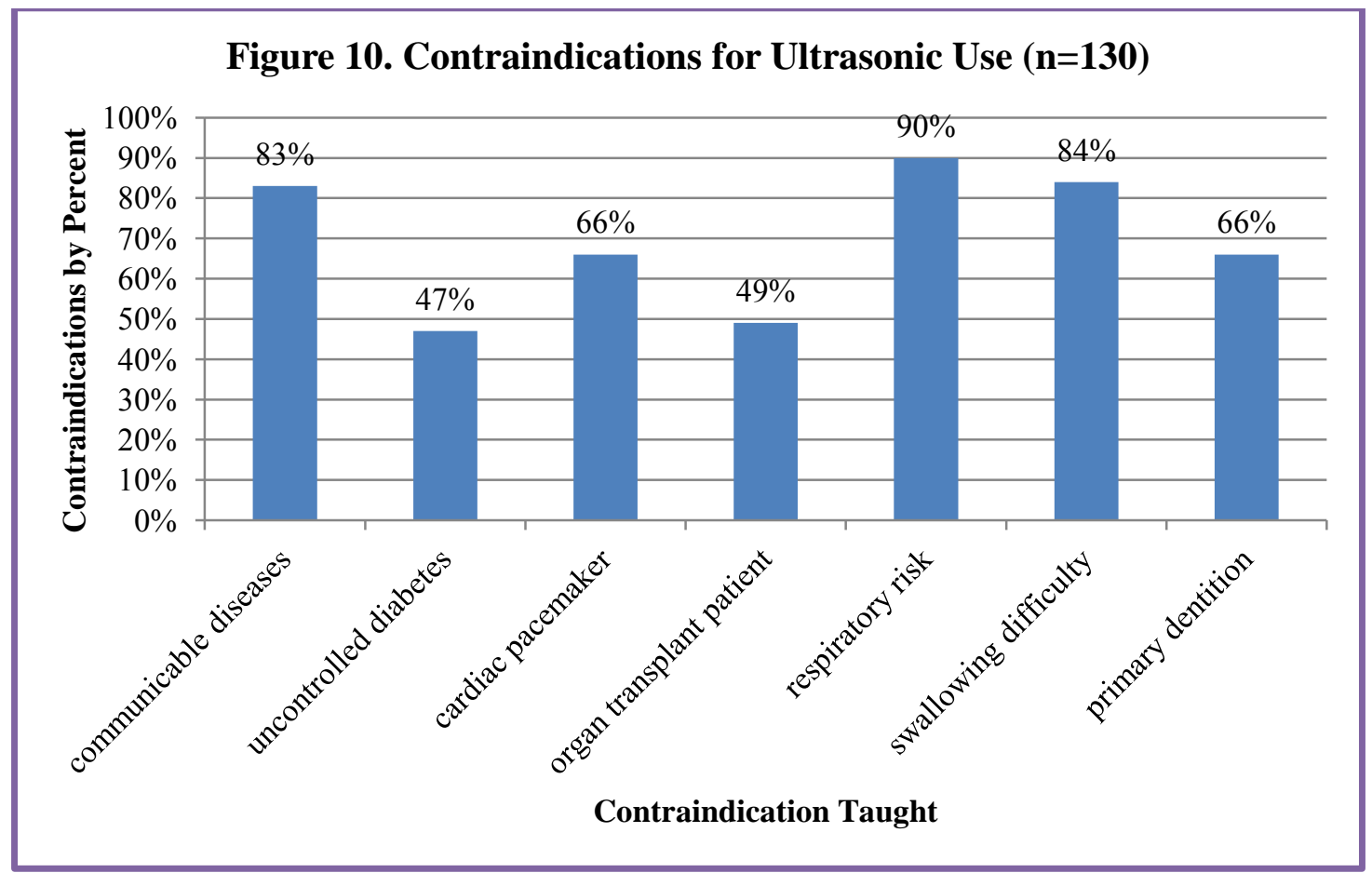


A measure of competency is necessary to ensure students have learned proper techniques for using an ultrasonic scaler. Programs used more than one type of measurement. (Figure 11.) Some programs indicated use of critical thinking narratives, which include determination of instrument selection, techniques, used and identification of correct treatment modalities for specific patients. Skill evaluation and self-evaluation were listed in addition to a written exam in didactic information. More than one answer could be selected therefore totals do not equal $100 \%$.

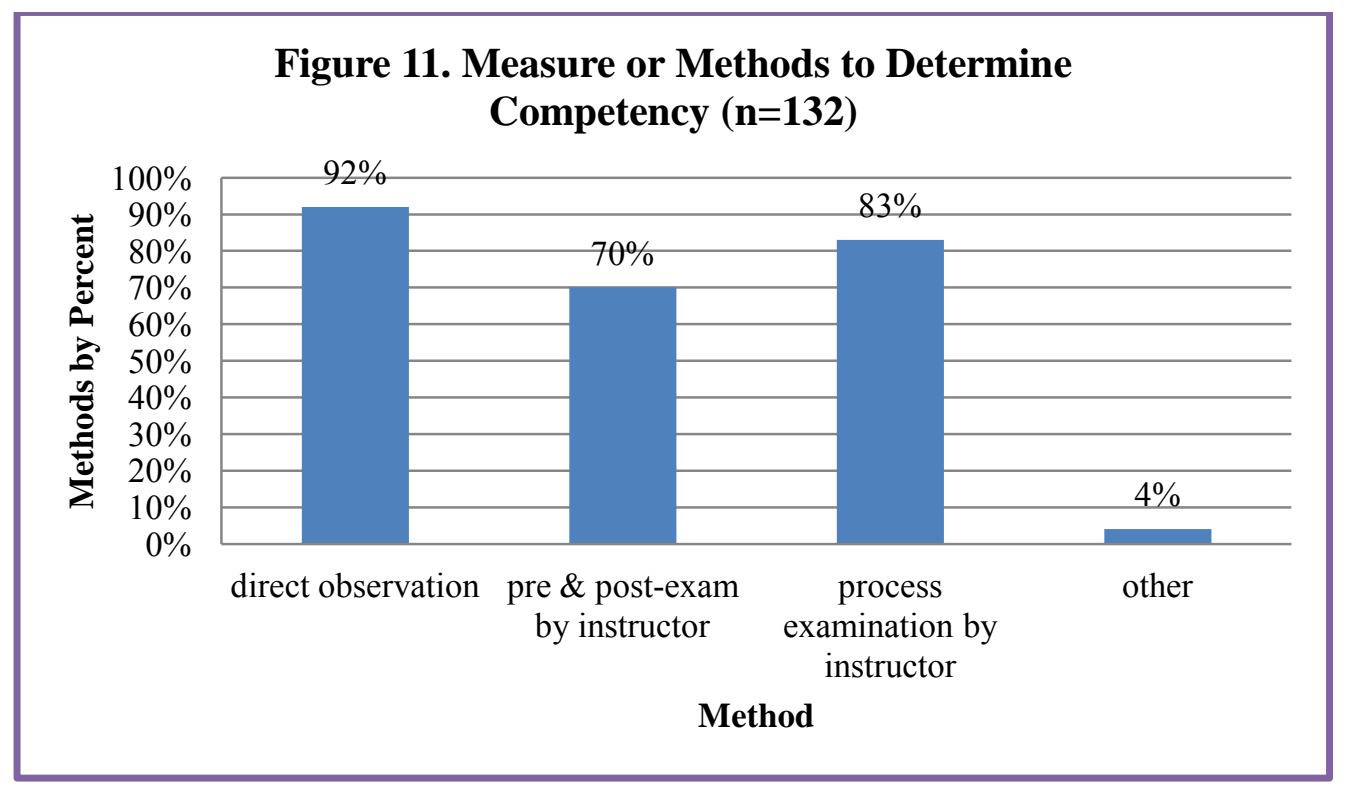

Magnetostrictive ultrasonic scalers were much more prevalent than piezoelectric ultrasonic scalers in dental hygiene programs. One hundred and twenty-seven programs (93\%) reported having magnetostrictive ultrasonic scalers. The ratio of magnetostrictive ultrasonic units to students was predominantly 1:1 with $80 \%$ of the programs selecting this answer. Ten percent choose the ratio of 1:2. The remaining ten percent ranged from 3:4 to $1: 15$. Six programs required students to purchase their own magnetostrictive ultrasonic scaler unit. One program 
gave students the option to buy their own magnetostrictive ultrasonic scaler unit.

Piezoelectric ultrasonic scalers were less common. Ninety-four programs (69\%) reported having piezoelectric ultrasonic scalers. One program required students to purchase a piezoelectric ultrasonic scaler. One respondent commented that after using the piezoelectric for three years, they were no longer going to use them and that part of the lack of success with using the piezoelectric was due to "the preference of faculty and their inability to adapt to a different technology." Six programs (5\%) had a 1:1 ratio and four programs had 1:4 ratio and another four programs had 1:5 ratio of piezoelectric ultrasonic scalers to students. Several programs stated they had a piezoelectric device for demonstration purposes or for students to gain experience. The remaining programs had ratios ranging from 5:8 to $1: 50$.

Most students (72\%) were required to purchase ultrasonic scaler tips or inserts while students in the dental hygiene programs. The survey asked what magnetostrictive inserts students were required to purchase and which inserts were provided by the program. (Figure 12.) The slim diameter straight tip was the most common choice for purchase by students and for programs to provide for students to use. More than one answer could be selected therefore totals do not equal $100 \%$. 


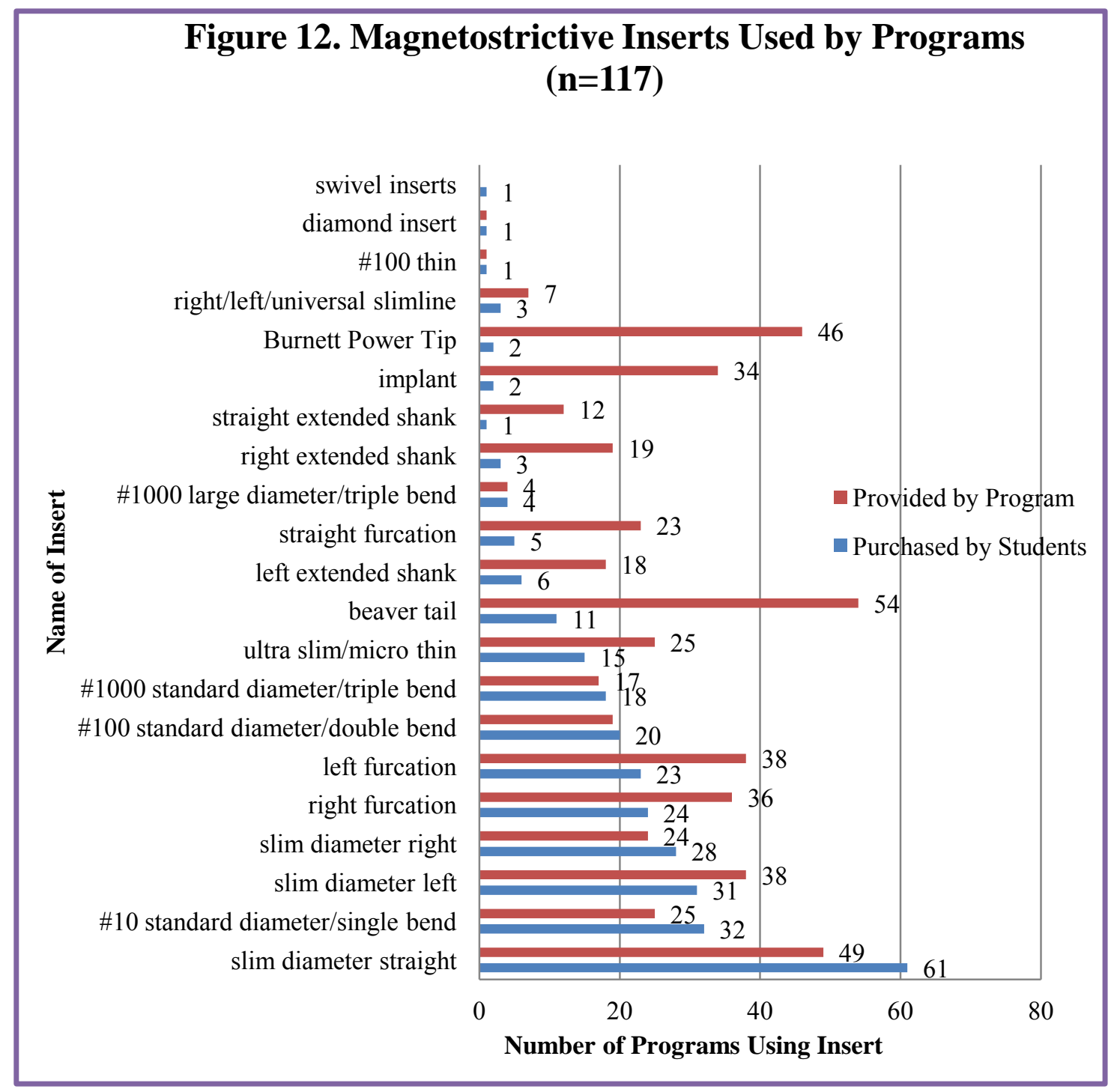

Most programs utilizing piezoelectric ultrasonic scalers provided the tips for students to use; others required students to purchase tips. A few programs provide tips, in addition to what the students were required to purchase. The diamond coated tip was used with supervision.

(Figure 13.) More than one answer could be selected therefore totals do not equal $100 \%$. 


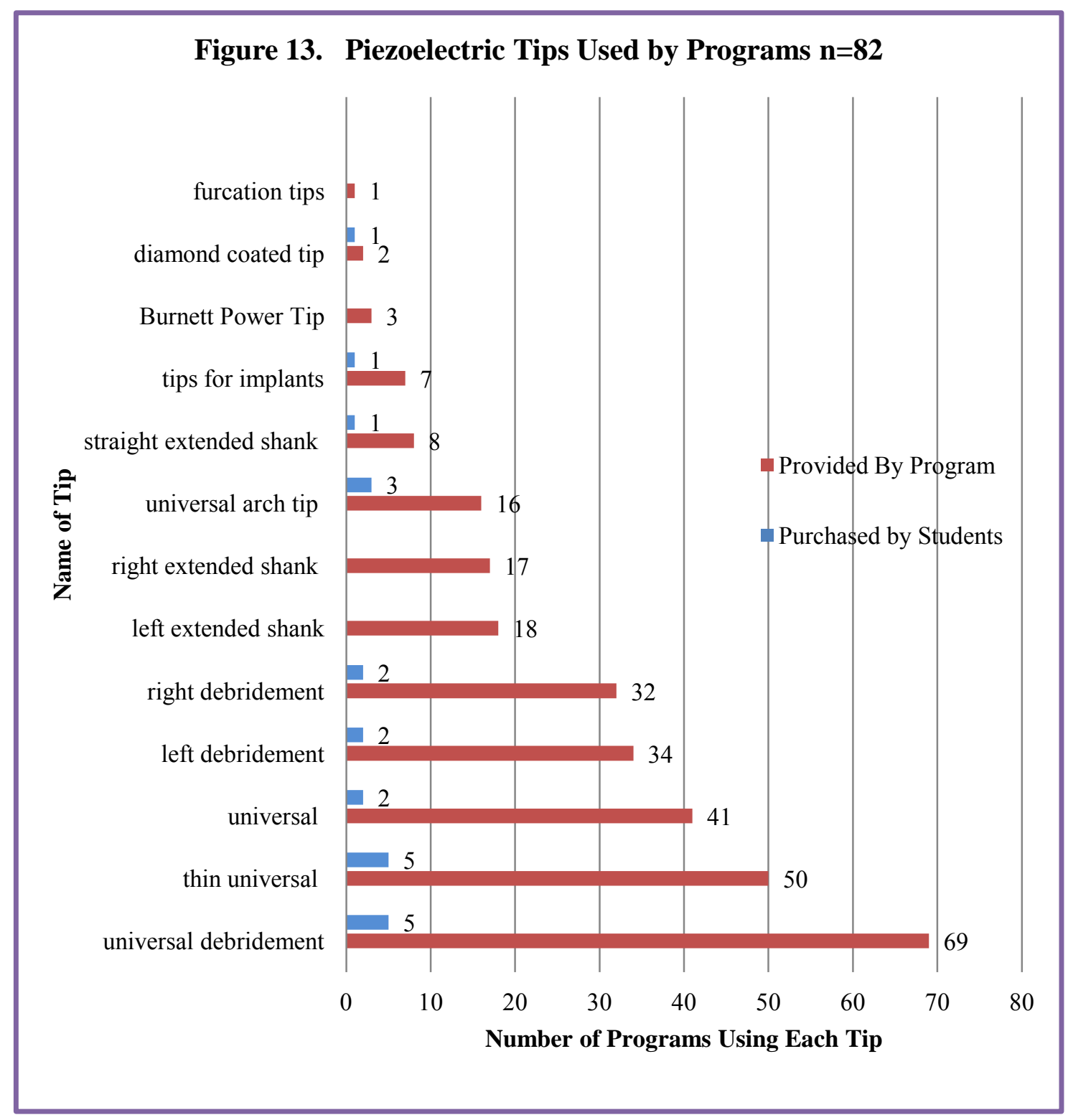

One hundred and eighteen (91\%) responded that students were taught to use of a wear guide to determine the wear of the ultrasonic scaler insert or tip. Ultrasonic units are stored chairside or in a dispensary to be check out for each use. Some programs stored units both chairside and in the dispensary. (Figure 14a., 14b.) More than one answer could be selected therefore total do not equal $100 \%$. 

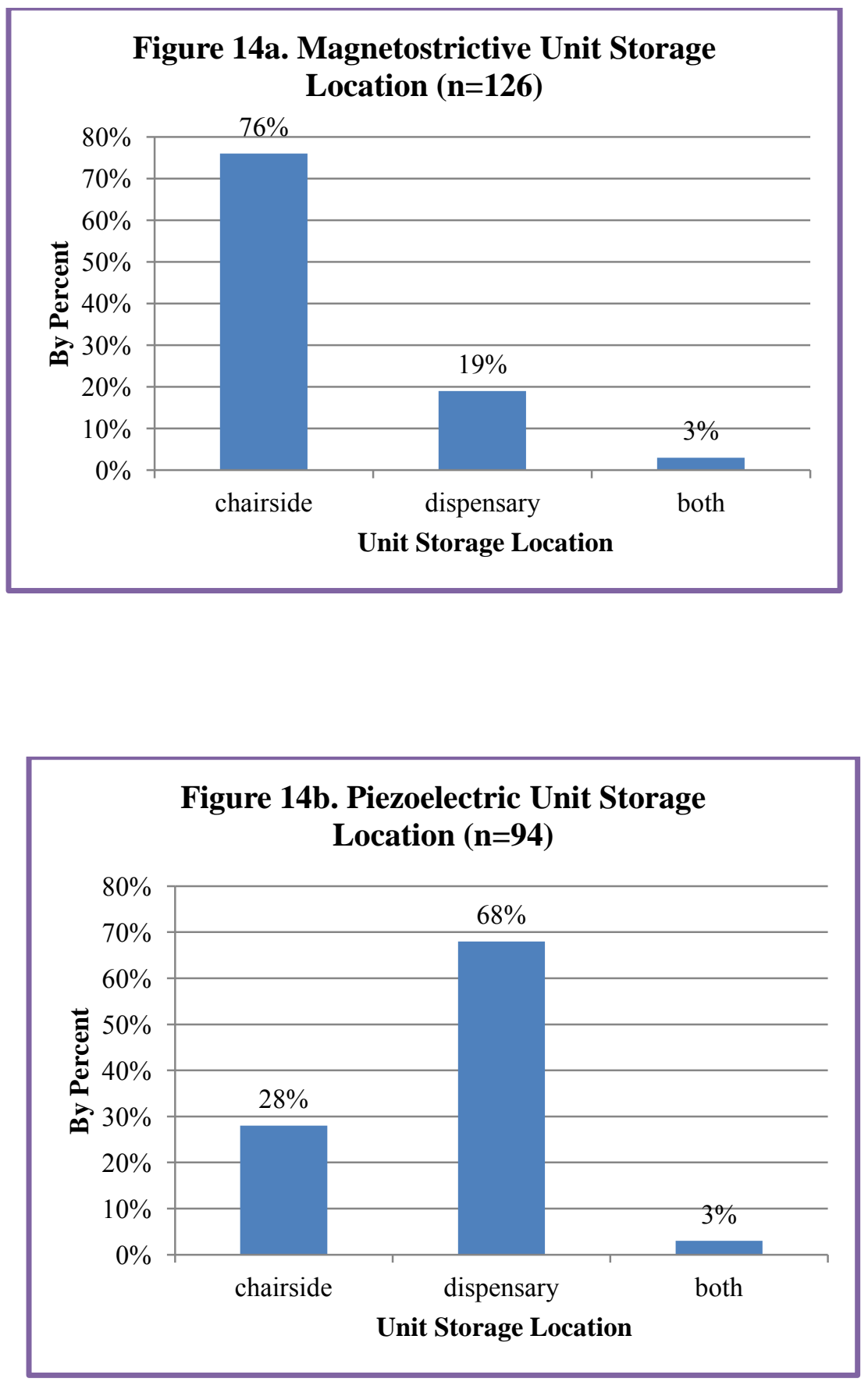

Some ultrasonic units have reservoirs for administering medicaments. Forty-six (35\%) responded that medicaments were used in the reservoirs. The most common medicament used was chlorhexidine gluconate. (Figure 15.) More than one answer could be selected therefore totals do not equal $100 \%$. 
Figure 15. Medicaments Used as Lavage $(n=106)$

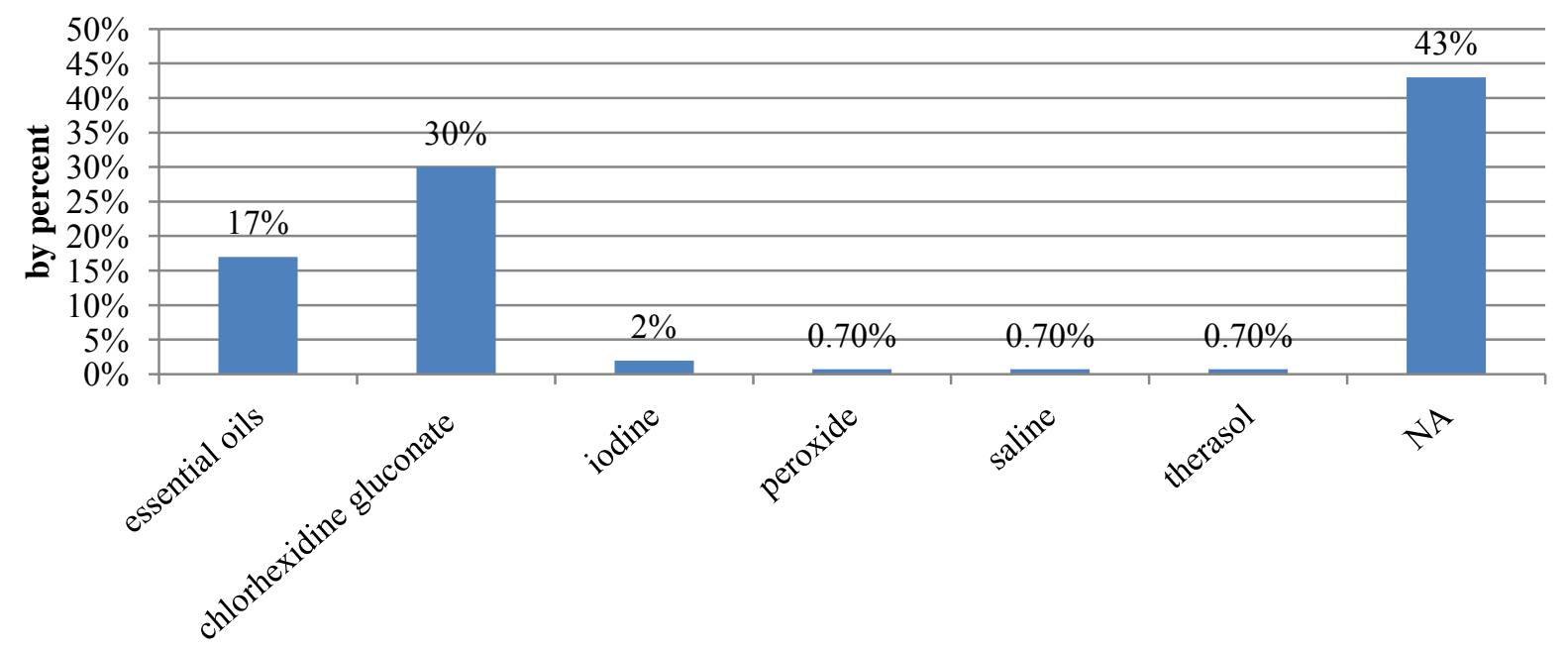

Medicament

Several methods are used to control the aerosol produced by ultrasonic scalers. (Figure 16.) The Blue Boa ${ }^{\circledR}$ HVE (high volume evacuation) is an adaptor that attaches to the high volume suction. The Blue Boa ${ }^{\circledR}$ allows use of the HVE without an assistant. More than one response could be selected therefore responses do not total $100 \%$.

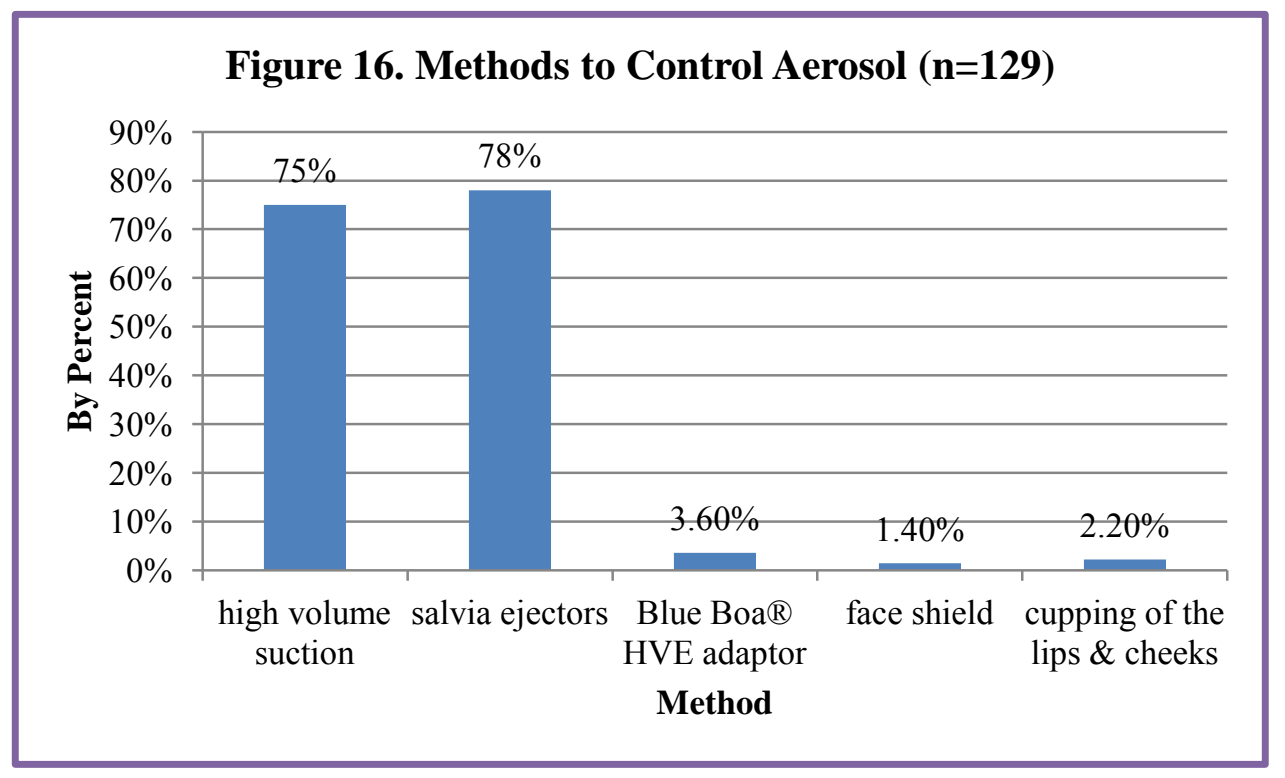


Students in $129(96 \%)$ programs are required to administer a pre-procedural mouth rinse to decrease the amount of bacteria in the mouth. Some programs have more than one rinse option available. (Figure 17.) Respondents could choose more than one answer therefore totals do not equal $100 \%$.

Figure 17. Pre-Procedural Mouth Rinses (n=129)

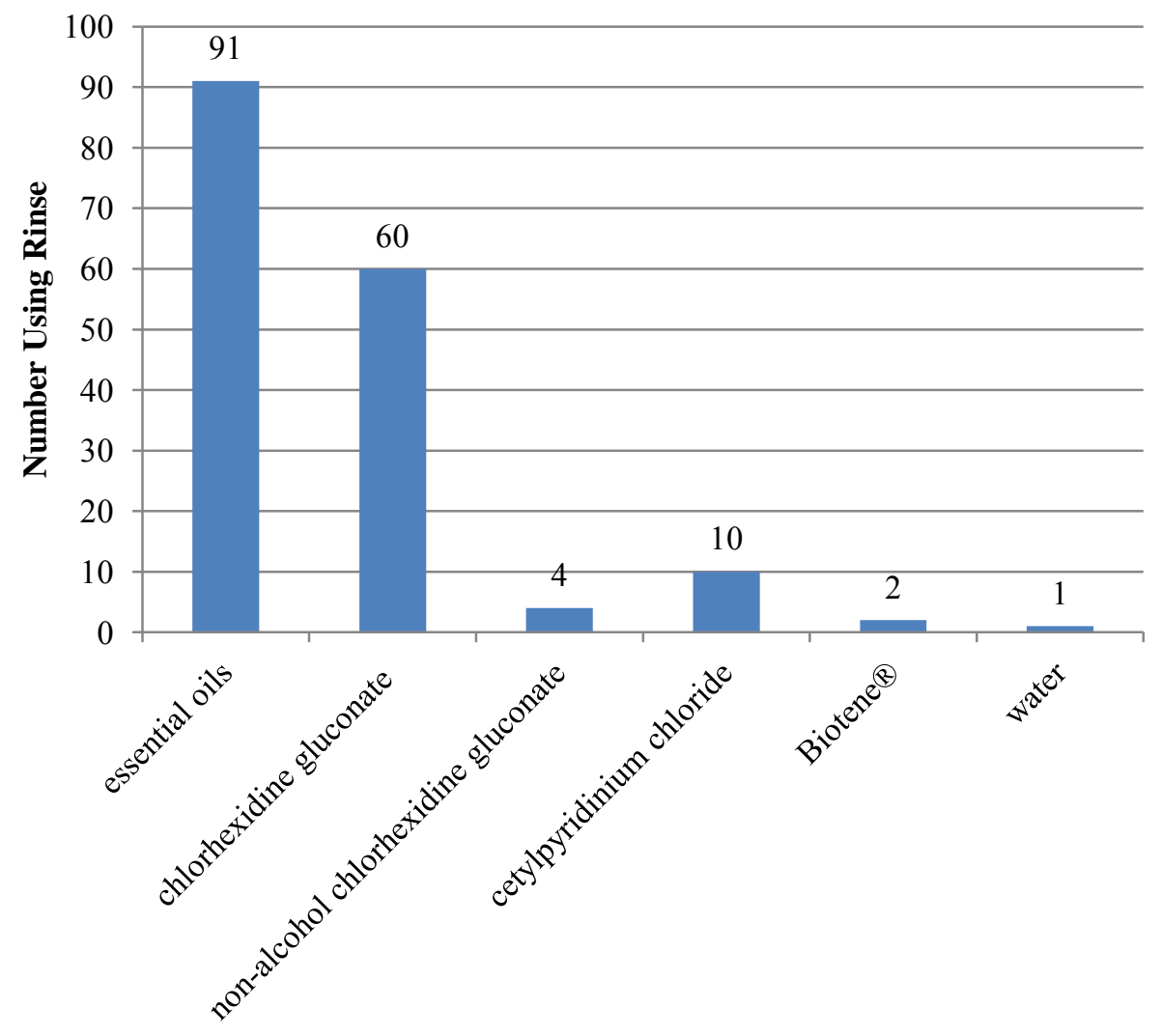

Pre-Procedural Rinse 
The majority of dental hygiene programs use a variety of methods for pain management. Some have more than one option available for students to administer. (Figure 18.) Other methods mentioned included one mention of a topical anesthetic cream containing $2.5 \%$ lidocaine and 2.5\% prilocaine. Another respondent answered transcutaneous electrical nerve stimulation (TENS) anesthesia and the WAND ${ }^{\text {TM }}$ computerized anesthesia, which is a local anesthesia injection delivery system. A third respondent reported the use of a Pro-Argin TM tooth desensitizing paste. Respondents could choose more than one answer therefore totals do not equal $100 \%$.

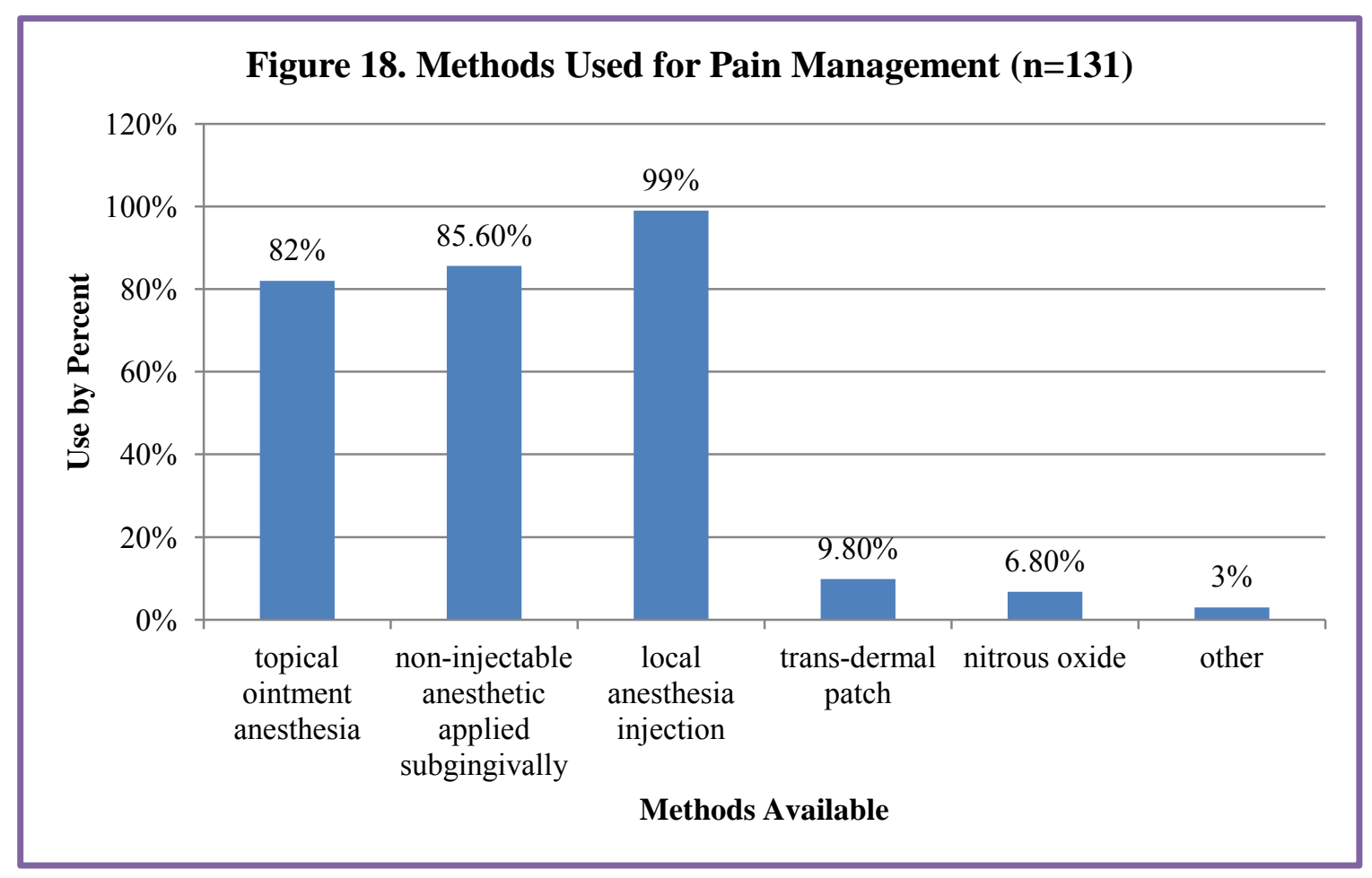

Programs provide student access to new technology. The most frequently mentioned were loupes and loupes with a light. A cavity detection was marked by seventy-five participants. Thirty participants reported the use of a brush biopsy. 


\section{Discussion}

This survey suggests that dental hygiene programs in the United States recognize the therapeutic value of the ultrasonic scaler. Numerous studies have shown the positive therapeutic benefit of the ultrasonic scaler. In addition to being less damaging to the tooth surface than hand scaling, ultrasonic scaling is equal to hand scaling for disrupting and removing biofilm, the acknowledged cause of periodontal disease. Respondents (68.7\%) answered that their program placed equal emphasis on ultrasonic scaling instrumentation instruction and hand scaling instrumentation instruction. They also stated that ultrasonic scaling instruction was included in most other courses in the curriculum. While respondents replied that their programs placed equal emphasis on ultrasonic scaling instruction and hand scaling instruction, the majority $(77.44 \%)$ do not include ultrasonic scaling instruction during preclinical instruction. Most programs (89\%) provide hand scaling instruction prior to ultrasonic scaling instruction. Only $22.9 \%$ introduce ultrasonic scaling instruction in the first term of clinical instruction. Slightly more than half of the programs responding (51.1\%) introduce ultrasonic scaling instruction in the second clinical term, with $22.1 \%$ introducing ultrasonic scaling instruction in the third clinical term and $3.8 \%$ introducing it in the last clinical term. This suggests a disconnect between what is written in scientific literature and what is actually practiced in dental hygiene programs. Once the ultrasonic scaler is introduced, programs encourage students to use it for all patients who do not exhibit contraindications. Most students have more than one term of clinical application of the ultrasonic scaler on patients by graduation.

Magnetostrictive ultrasonic scalers are readily available in $93 \%$ of programs with most stored chairside for students to use. Eighty percent of the programs report a 1:1 ratio of students to magnetostrictive units with another $10 \%$ reporting a 2:1 ratio. Six programs require students to purchase a magnetostrictive ultrasonic unit with another program offering the option of purchase. Piezoelectric ultrasonic scalers were available in $69 \%$ of programs, with a high student to piezoelectric unit ratio. Piezoelectric scalers are used primarily as enrichment experience with most stored in a dispensary. The piezoelectric ultrasonic scaler was developed in Europe and is more predominate there while the magnetostrictive was developed in the 
United States. This may explain the lack of piezoelectric ultrasonic scalers available in dental hygiene programs.

Respondents agree that most patient profiles benefit from the use of the ultrasonic scaler and students are taught to utilize the American Dental Association periodontal case types as criteria for using the ultrasonic scaler. The amount of calculus was cited as one criteria for use of the ultrasonic scaler by $97.82 \%$ of respondents. However, only $31 \%$ chose inflammation as criteria for ultrasonic debridement. Considering the vast amount of evidence demonstrating the role of inflammation in periodontal disease with biofilm, not calculus, as the primary etiological factor, this suggests that dental hygiene programs are still teaching a traditional approach to instrumentation. Traditionally, instrumentation has been approached based on the presence of clinically-detectable deposits, with the end point of therapy measured by the absence of clinically-detectable deposits. An approach that aligns with the current treatment philosophy of periodontal debridement would be based on thorough removal of biofilm, with the end point of therapy measured by resolution or absence of inflammation.

A variety of inserts and tips are available. Students are required to purchase some inserts and tips with programs providing additional inserts and tips. The most commonly purchased, and therefore assumed to be taught and utilized tip designs are straight: magnetostrictive slimline straight (50\%) and Burnett power tip (39\%), and piezoelectric universal debridement tip (64\%). The frequency of purchase (and assumed instruction and usage) of standard diameter tips for efficient removal of heavier deposits, as well as the frequency of purchase of curved slim diameter tips for efficient debridement of biofilm from contoured root surfaces is minimal, between $20 \%$ and $29 \%$.This suggests that dental hygiene programs are teaching a "one insert does all" approach to instrumentation instead of teaching the student to vary insert/tip diameter and shape according to type of deposit and anatomy of treatment site, which maximizes efficacy and efficiency of deposit removal and minimizes root surface damage and the chance of burnishing calculus deposits. This suggests that dental hygiene education programs are not fully aligned with current treatment philosophy of periodontal debridement. 
Student competency is determined in a variety of ways including pre and post examination of the patient's mouth by instructor, direct observation, process examination by instructor, self-evaluation, critical thinking narratives and written exams on didactic information. Most programs (56\%) do not have a minimum requirement for students to use the ultrasonic scaler. The most common requirement by those who do have a minimum was two uses per term. It would be expected that higher minimum requirements for using the ultrasonic scaler would facilitate development of competency.

The ultrasonic scaler produces a bacteria laden aerosol which is a biohazard. Studies have shown that even though unseen by the naked eye, this aerosol often contains blood. ${ }^{35,41}$ This aerosol remains in the air for at least 30 minutes and up to 24 hours. The area of exposure to the aerosol can be up to 20 feet from the treatment center. High volume evacuation is necessary for effective control of aerosol. Dental hygiene programs use more than one method for aerosol control. Seventy-five percent of the dental hygiene programs use high volume evacuation. Seventy-eight percent use salvia ejectors which are not effective in controlling the bacteria laden aerosol. The Blue Boa ${ }^{\circledR}$ HVE is an adaptor attached to the high volume evacuation that can be used without an assistant. It is effective in controlling the bacteria laden aerosol. The Blue Boa ${ }^{\circledR}$ HVE is used by $3.6 \%$ of dental hygiene programs. Programs need to address the issue of the biohazard created by the ultrasonic scaler aerosol and instruct and implement proper infection control of the aerosol. Studies have shown that a pre-procedural mouth rinse reduces the amount of bacteria released in the air with two-30 second rinses more effective than one-30 second rinse. ${ }^{41}$ A pre-procedural mouth rinse is used by $96 \%$ of dental hygiene programs using a variety of rinses with $91 \%$ using essential oils and $64 \%$ using chlorhexidine gluconate with or without alcohol. Studies have found no difference in the effect of chlorhexidine with alcohol compared to chlorhexidine without alcohol. ${ }^{9}$

According to the answers selected by respondents in this survey, $66 \%$ of dental hygiene programs teach the use of ultrasonic scaling as a contraindication on patients with implanted pacemakers. This question did not delineate between magnetostrictive and piezoelectric ultrasonic scalers. The current 
dental literature is inconclusive on this issue. The piezoelectric ultrasonic scaler is not contraindicated because it does not create an electromagnetic field.

To conclude, the majority of dental hygiene programs responding to the survey use similar methods, textbooks, and criteria for teaching ultrasonic scaler instrumentation. While the respondents indicated that their program placed equal emphasis on ultrasonic scaling instrumentation instruction and hand scaling instrumentation instruction, in practice, manual instrumentation instruction was presented in pre-clinic and taught prior to ultrasonic instrumentation. Additionally, most programs have only minimal, if any, student requirement for ultrasonic scaler instrumentation use. This indicates a greater emphasis on manual instrumentation instruction despite a philosophical shift in periodontal instrumentation. Almost all programs cite calculus as a criterion for using the ultrasonic scaler with just less than a third citing inflammation as a criteria for using an ultrasonic scaler. Programs need to realign the criteria with the evidence-based current philosophy of periodontal therapy recognizing the key role of inflammation.

Programs need to reevaluate the infection control procedures for the bacteria laden aerosol released by the ultrasonic scaler using evidence-based information. Programs need to revaluate the inserts and tips taught and align the teaching practices of the dental hygiene programs with current evidence-based literature, which supports the use of inserts/tips of variable diameters and shapes to optimize thorough debridement and minimize damage to the root surface.

The use of piezoelectric ultrasonic scalers poses no risk to patients with cardiac pacemakers. The literature is inconclusive on the use of magnetostrictive ultrasonic scalers. Major cardiac pacemaker manufacturers state that the use of the magnetostrictive ultrasonic scaler is safe to use on patients with implanted cardiac pacemakers. 


\section{Chapter 5}

\section{Summary and Conclusions}

Currently, there is no research available defining a consensus of instruction for ultrasonic instrumentation in dental hygiene programs. An email survey of all dental hygiene programs in the United States was conducted. The results of this study can be summarized as follows:

1. Dental hygiene programs state that equal emphasis is place on hand scaling and ultrasonic scaling instrumentation instruction.

2. The majority of dental hygiene programs introduce hand scaling instrumentation instruction in pre-clinic prior to the introduction of ultrasonic instrumentation instruction. Ultrasonic scaling instruction is not usually included in pre-clinic.

3. A variety of resources and strategies are employed for teaching ultrasonic scaler instrumentation including the use of the following:

a. typodont

b. student partners

c. clinical patients

d. teeth painted with nail polish, teeth with simulated calculus and striped birthday candles

e. a hotdog to visualize the effects on soft tissue

f. an aluminum can to demonstrate the power of the tip

g. You Tube and videos 
h. guest speakers from ultrasonic companies

4. Criteria for choosing an ultrasonic scaler include:

a. amount and type of calculus

b. amount and type of stain

c. periodontal disease classification

e. degree of inflammation

5. Student competency in the use of ultrasonic scalers is determined by a combination of the following:

a. direct observation

b. pre and post-examination of the patient's mouth by instructor

c. process examination by instructor

d. self-evaluation

e. critical thinking narratives

f. written exams on didactic information

6. Magnetostrictive ultrasonic scalers are readily available with $80 \%$ of the programs reporting a 1:1 ratio and another $10 \%$ reporting a $1: 2$ ratio of students to magnetostrictive ultrasonic scaler units. Some programs require students to purchase a magnetostrictive ultrasonic scaler unit. Piezoelectric ultrasonic scalers were less common with a high ratio 
of students to piezoelectric ultrasonic scalers. The piezoelectric ultrasonic scalers were available primarily for students to experience as enrichment.

7. The magnetostrictive ultrasonic scaler inserts most commonly required to be purchase by students are:

a. slim diameter straight

b. slim diameter left and right

c. \#10 standard diameter/single bend

8. Most common magnetostrictive ultrasonic scaler inserts provided by the programs are:

a. beavertail

b. slim diameter straight

c. Burnett Power Tip

d. furcation tip

c. slim diameter left and right

9. The piezoelectric ultrasonic scaler tips most commonly provided by the programs are:
a. universal debridement
b. thin universal
c. debridement left and right 
10. The Nield-Gehrig textbook is most universally used. The textbook by Wilkins is frequently used along with the Nield-Gehrig textbook. A third textbook by Darby and Walsh is also used in conjunction with the Nield-Gehrig textbook, but to a lesser degree.

11. The use of pre-procedural rinses and methods for containment of aerosol to reduce bacteria laden aerosol are taught by the majority of programs.

12. Students have access to many types of new technology.

13. Students use high volume evacuation suction with an adaptor to contain the aerosol produced to minimize the amount of bacteria laden aerosol entering the air.

14. Medicaments are used as an adjunct to the periodontal therapy. There is often more than one type of pain management option available.

15. More programs are trying to develop critical thinking skills, which are necessary for evaluating ever-changing information. It also gives students a base to develop a plan of action when encountering something new or out of the ordinary once in private practice.

\section{Conclusions}

Based on the data collected, literature reviewed, and the investigator's experience, the following can be concluded:

1. Dental hygiene programs universally provide ultrasonic scaling instruction in their curriculum and have embraced the use of ultrasonic scalers in direct patient care and treatment. 
2. Dental hygiene educators state that equal emphasis is placed on ultrasonic scaling instrumentation and hand scaling instrumentation, but in practice, hand scaling instruction is provided in pre-clinic prior to ultrasonic scaling instruction.

3. Preclinical instrumentation instruction does not universally include ultrasonic instrumentation instruction in dental hygiene education programs nationally. Most programs have minimal, if any, requirements for student utilization of the ultrasonic scaler. This suggests a greater emphasis on manual instrumentation despite the philosophical shift in periodontal instrumentation.

4. Pre-procedural mouth rinses and high volume evacuation to control bacteria laden aerosol produced by the ultrasonic scaler are commonly employed nationally by dental hygiene programs.

5. The magnetostrictive ultrasonic scaler is utilized with greater frequency than the piezoelectric devices in dental hygiene education programs nationally.

6. The most commonly available and therefore assumed to be taught and utilized in dental hygiene programs are straight designs: magnetostrictive slimline straight and the Burnett power tip, and the piezoelectric universal debridement tip. This suggests that dental hygiene programs are teaching a one insert/tip does it all approach to instrumentation instead of teaching selection of appropriate tip design based on the type of deposit and anatomy of the site to be treated. This suggests a disconnect with what is practiced in dental hygiene programs nationally and the current philosophy written in scientific literature.

7. Current scientific literature is inconclusive on the use of magnetostrictive ultrasonic scaler use on patients with implanted cardiac pacemakers. Predominate cardiac pacemaker manufacturers 
state that the magnetostrictive ultrasonic scalers pose no risk to patients with cardiac pacemakers. The piezoelectric ultrasonic scaler does not produce and electromagnetic field and therefore the use of the piezoelectric ultrasonic scaler poses no risk to the patient with an implanted cardiac pacemaker. 


\section{Recommendations for Future Studies}

1. A future study would likely yield a higher participant response if presented during the regular school year.

2. A study could be conducted of final semester dental hygiene students to investigate their cognition of the justification for utilizing the ultrasonic scaler, the justification for the preprocedural mouthrinses, their understanding of the aerosol produced by ultrasonic scaler as a biohazard and how to best to manage the aerosol produced.

3. A future study could examine in more detail the infection control practices when using the ultrasonic scaler.

4. A study could be conducted of practitioners five years post graduation to investigate their ultrasonic scaling practices.

5. A peripheral study could be conducted regarding the use of other technologies in dental hygiene education. 


\section{References}

1. Johnson WN, Wilson JR. The application of the ultrasonic dental unit to scaling procedures. J of Periodontol. 1957;28:264-71.

2. Matsuda S. Ultrasonics for periodontal therapy. Access. September-October 2010;24:40-42

3. American Academy of Periodontology. Position paper: Sonic and ultrasonic scalers in periodontics. Periodontol 2000:71;1792-1801.

4. Lea SC, Walmsley AD. Mechano-physical and biophysical properties of power-driven scalers: driving the future of powered instrument design and evaluation. Periodontol 2000. 2009; 51: $63-78$.

5. Nield-Gehrig JS. Fundamentals of Periodontal Instrumentation. Baltimore, MD: Lippincott; 2008:538-565.

6. Smart GJ, Wilson M, Davies EH, Kieser JB. The assessment of ultrasonic root surface debridement by determination of residual endotoxin levels. J Clin Periodontol. March 1990; 17(2):174-178.

7. Fleming TF, Petersilka G, Mehl A, et al. Working parameters of a sonic scaler influencing root substance removal in vitro. Clin Oral Invest. 1997;1:55-60.

8. O'Hehir T. Gross scaling: an antiquated concept. Dental Hygienist News. Winter 1994; $7: 19-20$.

9. Carr M. Ultrasonics. Access. May-June 1999;22(Special Suppl):2-9. 
10. Arabaci T, Cicek Y, Canakci CF. Sonic and ultrasonic scalers in periodontal treatment: A review. Int J of Dental Hyg. February 2007;5:2-12.

11. Drisko CH. Sonic and ultrasonic scaler in periodontics. J of Periodontol. November 2000; 71:1792-01.

12. Gurenlian JR. The role of dental plaque biofilm in oral health. J Dental Hyg. October 2007; 81(5):1-12.

13. Khosravi M, Bahrami ZS, Atabaki MSJ, Shokrgozar MA, Shokri F. Comparative effectiveness of hand and ultrasonic instrumentations in root surface planing in vitro. $J$ of Clin Periodontol. March 2004;31:160-165.

14. Tunkel J, Heinecke A, Flemming TF. A systematic review of efficacy of machine-driven and manual subgingival debridement in the treatment of chronic periodontitis. $J$ of Clin Periodontol. 2002;29 (Suppl s3):72-81.

15. Walmsley AD, Lea SC, Landini G, Moses AJ. Advances in power driven pocket/root instrumentation. J of Clin Periodontol. September 2008;35:22-28.

16. Leon LE, Vogel RI. A comparison of effectiveness of hand scaling and ultrasonic debridement in furcations as evaluated by differential dark-field microsocopy. $J$ Periodontol. 1987;58:86-94.

17. Barendregt DS, Van Der Velden U, Timmerman MF, Van Der Weijden F. Penetration depths with an ultrasonic mini insert compared with a conventional curette in patients with periodontitis and in periodontal maintenance. J Clin Periodontol. January 2008;35:31-36. 
18. Cobb CM. Microbes, inflammation, scaling, and root planing, and the periodontal condition. J of Dental Hyg. October 2008;82 (Suppl 3):4-9.

19. Maguire B. The changing face of periodontal--care introducing an evidence-based approach to your practice. J of Practical Hyg. March-April 2003;12(2):11-13.

20. Noack B, Genco RJ, Trevisan M, Grossi S, et al. Periodontal infection contribute to elevated c-reactive protein level. J Periodontol. September 2001;72(9):1221-1227.

21. Walmsley AD, Laird WRE, Williams AR. Dental plaque removal by cavitational activity during ultrasonic scaling. J of Clin Periodontol. 1988;15:539-543.

22. Oosterwaal PJ. The effect of subgingival debridement with hand and ultrasonic instruments on the subgingival microflora. J of Clin Periodontol. 1987;14:528-533.

23. Nishihara T, Koseki T. Microbial etiology of periodontitis. Periodontol 2000. 2004; 36: 14-26.

24. Costerton W, Schaudinn C, Melrose D. Dental biofilms in the oral cavity. Dimensions Digest of Dental Hyg. January 2011:6-22.

25. Greenstein, G. Nonsurgical periodontal therapy in 2000: A literature review. J of Am Dent Assoc. November 2000; 31(11):1580-1592.

26. Kawanami M, Sugaya T, Kato S, Iinuma K, Tate T, Hannan MA, et al. Efficacy of an ultrasonic scaler with a periodontal probe-type tip in deep periodontal pockets. Adv Dent Rest. November 1988;2 (2):405-410.

27. Kinan DF. Single-visit, full-mouth ultrasonic debridement: A paradigm shift in periodontal therapy? J Clin Periodontol. July 2005;32:732-733. 
28. Ryan ME. Nonsurgical approaches for the treatment of periodontal diseases. Dent Clin N Am. 2005;49:611-636.

29. Chapple IL, Walmsley AD, Saxby MS, Moscrop H. Effect of instrument power setting during ultrasonic scaling upon treatment outcome. J Periodontol. September 1996;66 (9): 756-760.

30. Fogel HM, Pashley DH. Effect of periodontal root planing on dentin permeability. J Clin Periodontol. 1993;20:673-677.

31. Fukazawa E, Nishimura K. Superficial cemental curettage: Its efficacy in promoting improved cellular attachment on human root surfaces previously damaged by periodontitis. J Periodontol. 1994;65:168-176.

32. DePaola LG, Spolarich AE. Safety and efficacy of antimicrobial mouthrinses in clinical practice. J of Dental Hyg. October 2007;81(5):1-17.

33. Wilkins EM. Clinical Practice of the Dental Hygienist. Baltimore, MD: Lippincott; 2009: 655-662.

34. Muhney K, Dechow P. Patients' perception of pain during ultrasonic debridement: a comparison between piezoelectric and magnetostrictive scalers. J of Dental Hyg. February 2010; 84:185-189.

35. Trenter SC, Walmsley AD. Ultrasonic dental scaler: associated hazards. J Clin Periodontol. February 2003;30(3):95-101.

36. Mengel R, Stelzel M, Mengel C, et al. An in vitro study of various instruments for root planing. Int. J Periodontics and Restorative Dentistry. 1997;17(6):592-599. 
37. Young N, O'Heir TE. Periodontal debridement. In: Woodall IR: Comprehensive Dental Hygiene Care. St. Louis, IL: Mosby-Year Book, Inc.;1993:533-570.

38. Brame JL. Advances in ultrasonics. Dimensions of Dental Hyg. October 2010;8:48-57.

39. Leyes Borrajo JL, Garcia VL, Lopez CG, Rodriques-Nuñez I, Garcia FM, Efficacy of chlorhexidine mouthrinses with and without alcohol: a clinical study. J of Periodontol. 2002; 73:317-321.

40. Fine DH, Mendieta C, Barnett ML, et al. Efficacy of preprocedural rinsing with an antiseptic in reducing viable bacteria in dental aerosols. $J$ of Periodontol. 1992;63(10):821-824.

41. Barnes JB, Harrel SK, Rivera-Hidalgo F. Blood contamination of the aerosols produced by in vivo use of ultrasonic scalers. J Periodontol. April 1998;69(4):434-438.

42. King TB, Muzzin KB, Berry CW, Anders LM. The effectiveness of an aerosol reduction device for ultrasonic scalers. J Periodontol. January 1999;70(1):473-477.

43. Harrel SK, Barnes JB, Rivera-Hidalgo F. Aerosol and splatter contamination from the operative site during ultrasonic scaling. J of Am Dental Assoc 1998;129(9):1241-1249.

44. Scannapieco FA. Role of oral bacteria in respiratory infection. J Periodontol. July 1999; 70(7):793-802.

45. St. Jude Medical, Inc. http://health.sjm.com Pacemakers. Accessed 11.01.2011.

46. Medtronic, Inc. http://medtronic.com/patients/bradycardia/living-with/daily-living/index.htm accessed 12.02.2011. 
47. Boston Scientific EMI.

www.bostonscientific.com/templatedata/imports/HTML/CRM/patient/ accessed 12.02.2011.

48. Miller CS, Leonelli FM, Latham E. Selective interference with pacemaker activity by electrical dental devices. Oral Surg Oral Med Oral Pathol Oral Radiol Endod.1998;85(1): $33-36$.

49. Patel D, Glick M, Lessard E, Zaim S. Absence of in vivo effects of dental instruments on pacemaker function. Oral Surg Oral Med Oral Pathol Oral Radiol Endod. 2005;99(4):430.

50. Brand HS, vander Hoeff EV, Schrama TA, Entjes ML, van Nieuw AA. Electromagnetic interference of electrical dental equipment with cardiac pacemakers [in Dutch]. Ned Tijdschr Tandheelkd 2007;114(7): 373-376.

51. Roedig, JJ, Shah J, Elayi CS, Miller CS. Interference of cardiac pacemaker and implantable cardioverter-defibrillator activity during electronic dental device use. J of Am Dent Assoc. $2010 ; 141(5) ; 521-526$. 
APPENDIX A

IRB Letter of Exemption 


\section{W-WestliriginiaUniversity \\ Office of Rescarch Complianec}

\section{IRB Protocol-Exemption}

To: $\quad$ DeBiase, Christina

From: $\quad$ WVU Office of Research Compliance

Date: $\quad$ Wednesday, May 25, 2011

Subject: Exemption Acknowledgement

Tracking \#: $\mathrm{H}-23210$

Title: $\quad$ Ultrasonic Scaler Instumentation in Dental Hygiene Programs in the United States

The above-referenced study was reviewed by the West Virginia University Institutional Review Board (IRB) and was granted exemption in accordance with 45 CFR 46.101(2).

This protocol was reviewed using the following:

This research study was granted an exemption because the Research involves educational tests, survey procedures, interview procedures or observation of public behavior and (i) information obtained is recorded in such a manner that human subjects cannot be identified, directly or through identifiers linked to the subjects; and (ii) any disclosure of the human subjects' responses outside the research could not reasonably place the subjects at risk of criminal or civil liability or be damaging to the subjects' financial standing, employability, or reputation [45 CFR 46.101(2)]Exempt Research Checklist (210r)

The following documents have been acknowledged for use in this study and are available in the BRAAN system:

Surveys, Questionnaires, Interviews Attachments Hinchman cover letter.pdf Survey Hinchman.tt Survey Please note for future reference the old version of the cover letter should be deleted and not resubmitted with the revised version.

Thank you.

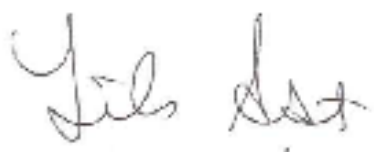

Board Designee: Ast, Lilo

Letter Sent By: Ast, Lilo, 5/25/2011 6:10 PM 
APPENDIX B

Survey 


\section{Ultrasonic Scaling Instruction in Dental Hygiene Programs in the United States}

1. * What degree/s in dental hygiene does your institution confer?

Г AS/AA, AAS

$\Gamma$ Certificate/ Diploma

- BS in Dental Hygiene, BSDH

Г MS in Dental Hygiene, MSDH

$\Gamma$ Other

2. If other degree, please specify.

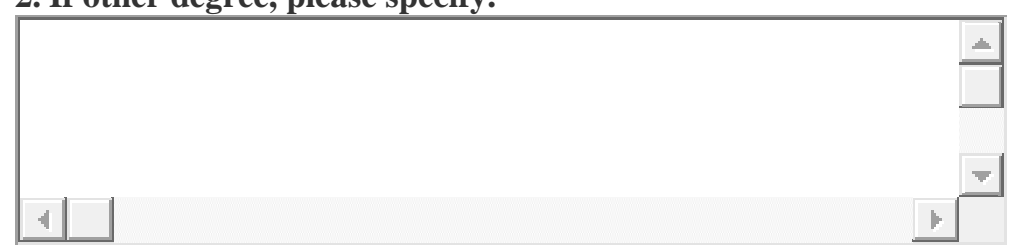

3. What is the typical number of terms needed to graduate including pre-requisite coursework?

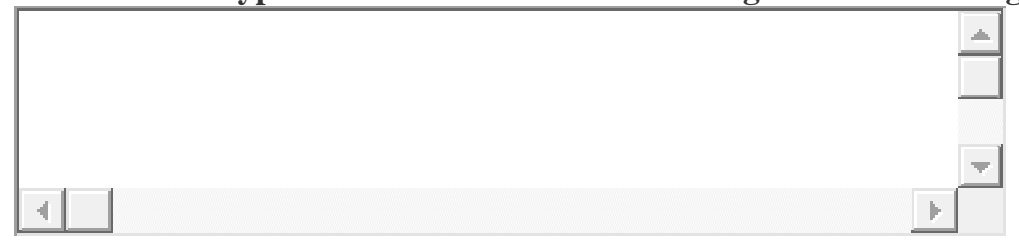

4. How is your school year divided?

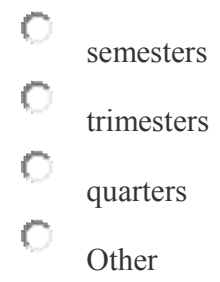

5. Does your dental hygiene curriculum require a summer session?

C. Yes

6. If the answer to number 5 is yes, how many summer sessions does your curriculum require?
C. One
T. Two
Three
Four 
7. In what region is your program located?

Northeast (Maine, New Hampshire, Vermont, Massachusetts, Rhode Island, Connecticut, New Jersey, New York, Pennsylvania )

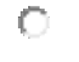

South (West Virginia, Virginia, Maryland, Delaware, Kentucky, Tennessee, Georgia, Alabama, Arkansas, Oklahoma, Mississippi, Florida, Louisiana, Texas, Washington, D. C.),

( Nebraska)

C

West (Montana, Wyoming, Colorado, New Mexico, Arizona, Idaho, Utah, Washington, Oregon, Nevada, California, Alaska, Hawaii),

8. Does your dental hygiene program have an onsite clinical teaching facility for students?

(C) Yes

**If the answer is no, then you have completed the survey. Thank you for your time.

9. Is your program associated with a dental school?

C yes

\section{Curriculum}

When answering questions 10 - 36 assume the clinical portion of dental hygiene education occurs over a two year period.

10. In which term is ultrasonic scaling theory introduced to your students?
(1st
(1) 2nd
(C) 3 rd
(1) 4 th

11. What textbooks are used for instruction of ultrasonic scaling instrumentation?
ए
Fundamental of Periodontal instrumentation by Nield-Gehrig
Г Clinical Practice of the Dental Hygienist by Wilkins
$\Gamma$ Dental Hygiene Theory and Practice by Darby \& Walsh

12. List other textbooks used for ultrasonic scaling instrumentation.

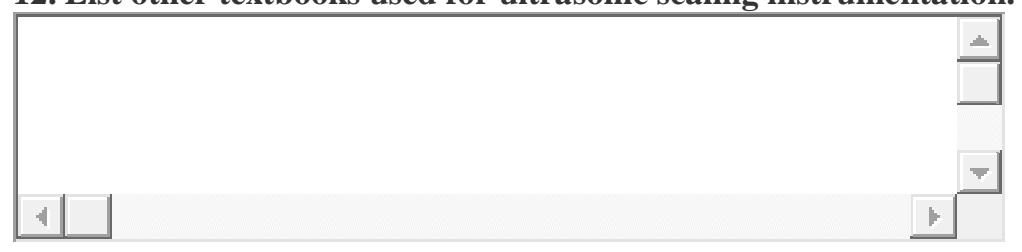


13. In which term do your students begin pre-clinical instrumentation?
(1st
2nd
3rd
4th
Other

14. If other was marked above, what term NOT listed, do your students begin pre-clinical instrumentation?

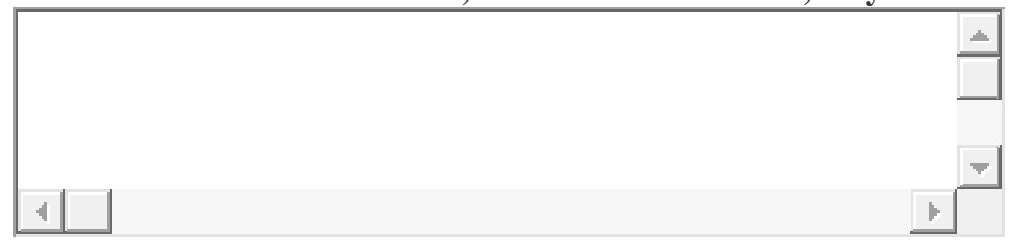

15. Is ultrasonic instruction included in pre-clinical instrumentation?

C Yes

16. When does your program provide hand scaling instrumentation instruction relative to ultrasonic scaling instrumentation instruction?
hand scaling before ultrasonic scaling
(
hand scaling after ultrasonic scaling
C
hand scaling and ultrasonic scaling concurrently

17. Which phrase correctly identifies the emphasis your program places on hand instrumentation versus ultrasonic instrumentation?
C
emphasis on hand instrumentation
C
emphasis on ultrasonic instrumentation
C
equal emphasis on hand instrumentation and ultrasonic instrumentation

18. Which term do students have actual clinical application of ultrasonics on patients? Mark all that apply.
Г2nd
Г 3rd
ए4th
$\ulcorner$ 5th

19. What are the criteria for a student to choose to use an ultrasonic scaler? Mark all that apply.

$\Gamma$ amount of calculus, check criteria listed below in question 20

$\Gamma$

amount of stain, check criteria listed below in question 21 
perio disease type, check criteria listed below in question 22

degree of inflammation, explain below in question 23

\section{Amount of calculus: Mark all that apply.}

- very light supragingival calculus, no sub gingival

- light supragingival calculus 1-2 mm wide, sheet calculus, subgingival calculus 1-2 mm into sulcus

supragingival tenacious calculus, black tenacious calculus on at least 3 teeth, or extending $5+\mathrm{mm}$

$\Gamma$

root debridement, 3-5 mm subgingivally

$\Gamma$

root debridement greater than $5 \mathrm{~mm}$ subgingivally

21. Amount of stain: Mark all that apply.

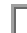

light localized or generalized stain

$\Gamma$

medium (dark stain covering at less than $1 / 3$ of clinical crown)

heavy, dark leathery black/brown stain covering more than $1 / 3$ of clinical crown

22. Perio diesease type: Mark all that apply.

Г

I

$\Gamma$ II

ए III

ए IV

23. If degree of inflammation, explain.

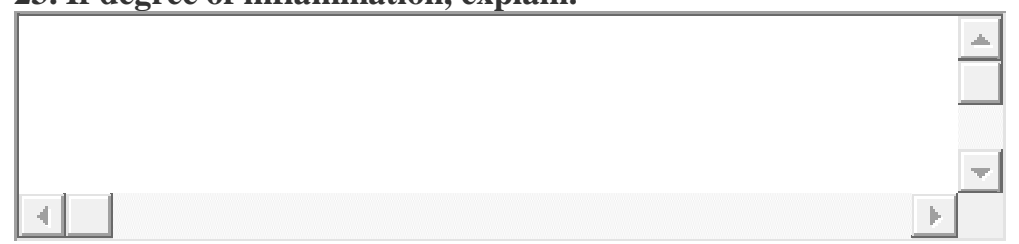

24. Is there a minimum clinical requirement for use of ultrasonic scalers?

(C) Yes

No

**If the answer to the above question is yes, what is the minimal clinical requirement? Fill in answers below.

25. Magnetostrictive minimum requirement

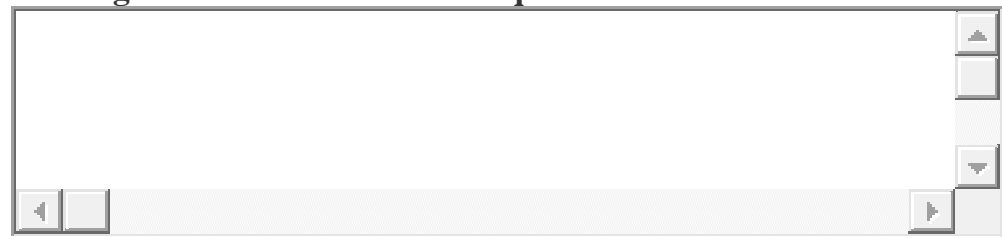


26. Piezoelectric minimum requirement

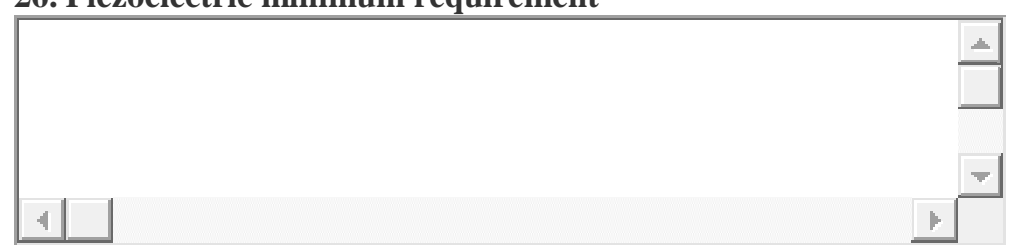

27. What courses include instruction on ultrasonic scaling instrumentation?

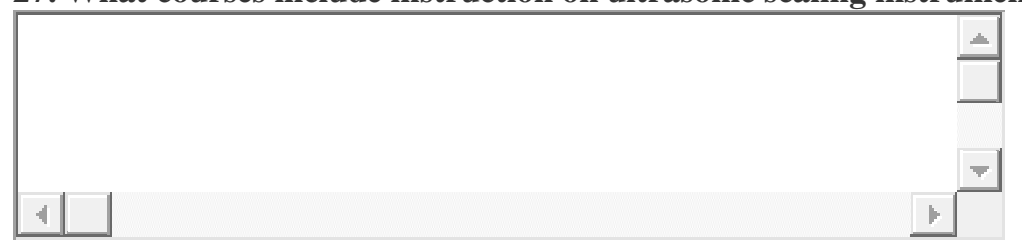

28. What types of teaching strategies are used to instruct students on ultrasonic instrumentation? Mark all that apply.

Г typodont

$\Gamma$ student partners

$\Gamma$ onsite clinic patients

$\lceil$ other, explain below

29. What other teaching strategies not listed above are used?

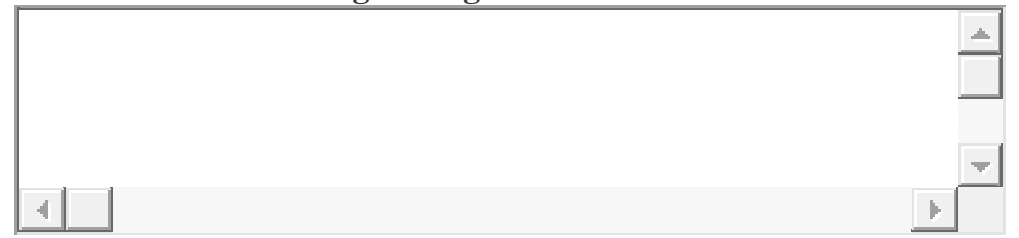

30. Which ultrasonic adaptation techniques are taught? Mark all that apply.

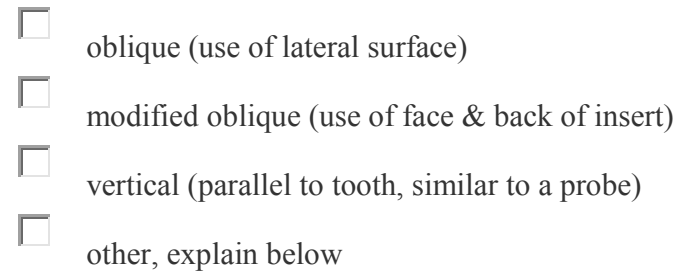

31. Explain other adaptation techniques taught.

32. Which ultrasonic scaling strokes are students taught to use? Mark all that apply.
$\Gamma$ horizontal
$\Gamma$ oblique
$\Gamma$ vertical
$\Gamma$ tapping
$\Gamma$ other, explain below 
33. What other ultrasonic scaling strokes not listed above, are students taught?

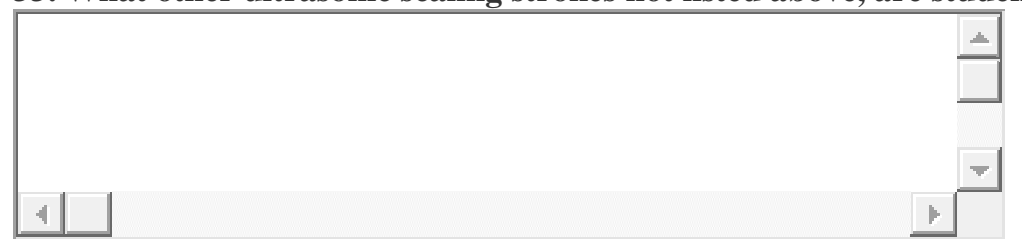

34. Which of the following are taught as contraindications for usage of ultrasonic instruments? Mark all that apply.

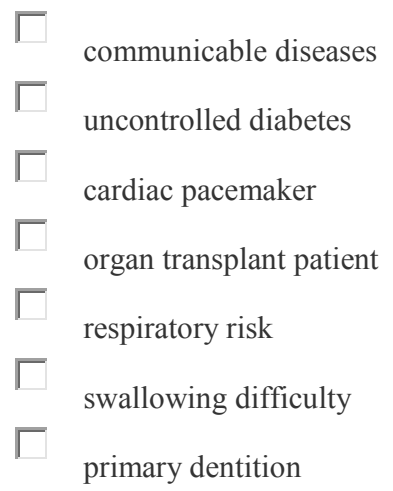

35. What measures or methods are used to determine competency in ultrasonic instrumentation? Mark all that apply.

Г

direct observation

$\Gamma$

pre- \& post-exam of patient by instructor

Г

process examination by instructor

Г

other, explain below

36. Explain what measures or methods, NOT listed above, are used to determine competency in ultrasonic instrumentation?

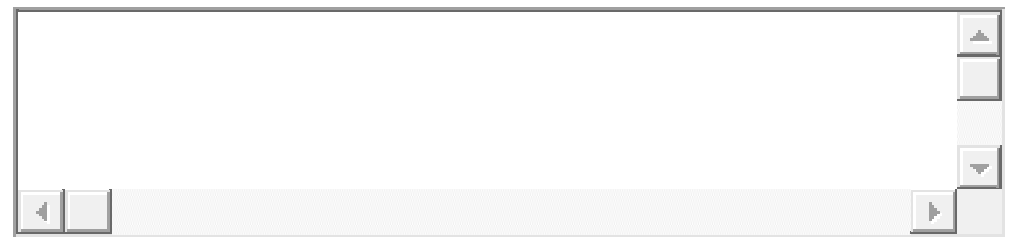

\section{Equipment}

37. What is the magnetostrictive unit to student ratio?

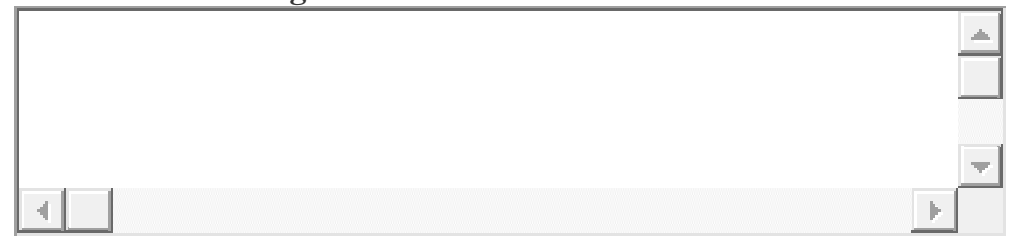


38. What is the piezoelectric ultrasonic unit to student ratio?

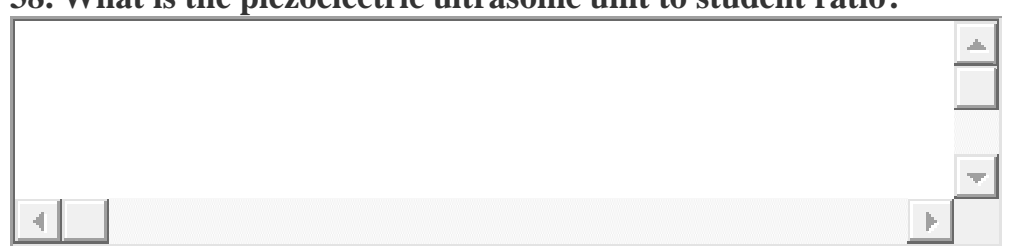

39. If your program has magnetostrictive ultrasonic scalers, which type?

Г 25k

Г 30k

$\lceil$ other, explain below

40. What magnetostrictive ultrasonic scaler, not listed above, does your program use?

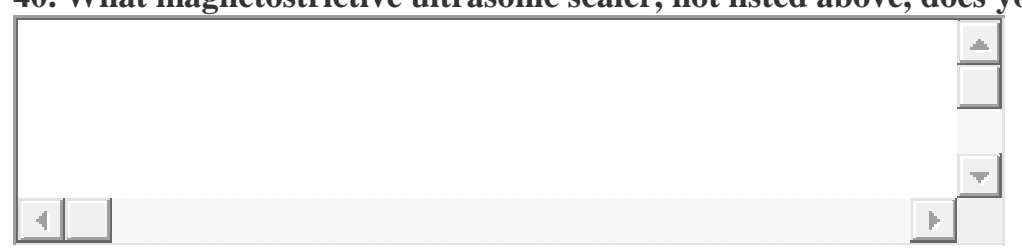

41. Are the ultrasonic magnetostrictive units secured chairside or stored in dispensary?

$\Gamma$ chairside

$\Gamma$ stored in dispensary

42. Are the ultrasonic piezoelectric units secured chairside or in dispensary?

$\Gamma$ chairside

$\Gamma$ stored in dispensary

43. Are students required to purchase ultrasonic tips or inserts? If no, proceed to questions 48 .

ГYes

ГNo

$\lceil$ supplied by program for use while in program

44. What magnetostrictive insert designs are students required to purchase? Mark all that apply.

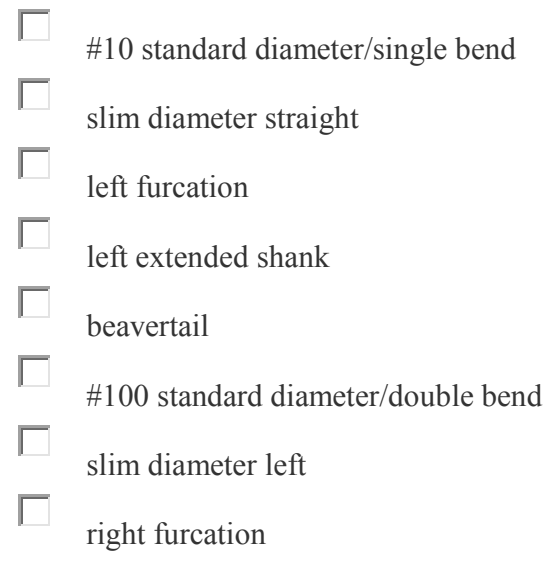




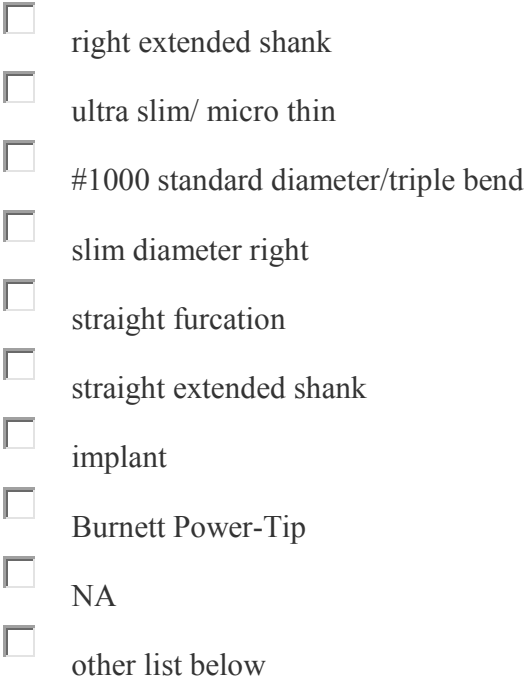

\section{List other inserts/comments}

\section{What piezoelectric tips are students required to purchase?}

$\Gamma \quad$ Burnett Power Tip
$\Gamma \quad$ universal debridement
$\Gamma \quad$ left extended shank
$\Gamma \quad$ universal arch tip
$\Gamma \quad$ left debridement
$\Gamma \quad$ right extended shank
$\Gamma \quad$ universal
$\Gamma \quad$ right debridement
$\Gamma \quad$ straight extended shank
$\Gamma \quad$ thin universal
$\Gamma \quad$ tips for implants
$\Gamma \quad$ NA
$\Gamma \quad$ other, list below

\section{List tips/comments}


48. What magnetostrictive insert designs does the program PROVIDE students to use while in the program?

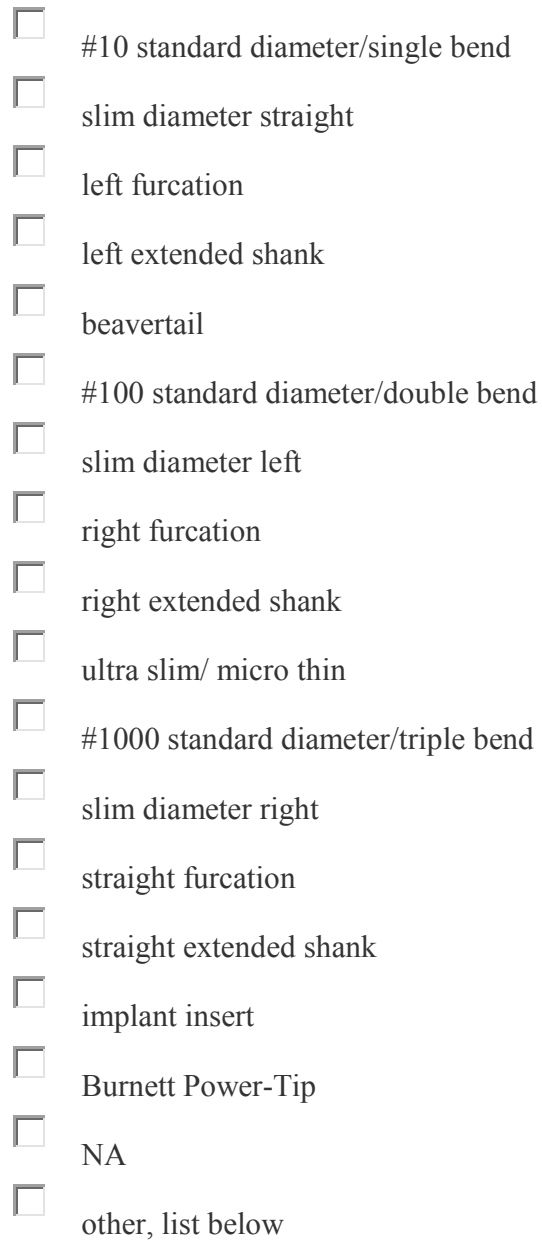

49. List other magnetostrictive inserts/comments 
50. What piezoelectric tips does the program PROVIDE students to use while in the program?

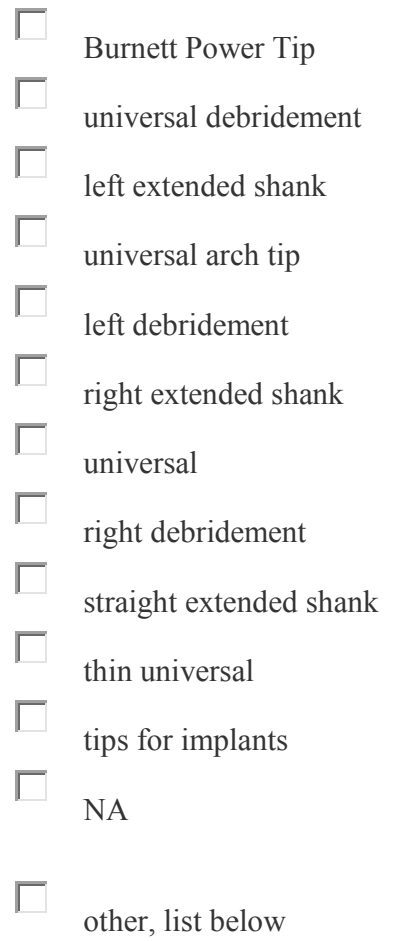

51. List other piezoelectric tips/comments.

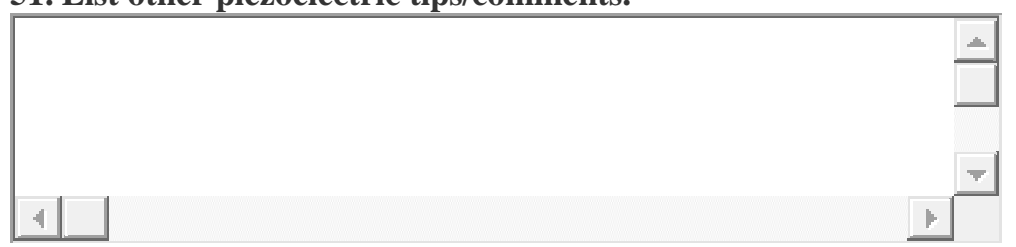

52. Are students taught to use a wear guide for ultrasonic inserts?

C Yes

(C)

53. Do the ultrasonic units have reservoirs for administering medicaments?

(C) Yes

54. What medicaments are available for students to use in the reservoir of the ultrasonic unit?
ए essential oils mouth rinse (Listerine)
Г chlorhexidine gluconate rinse
ए NA
एother, list below 
55. What medicaments are available, NOT listed above?

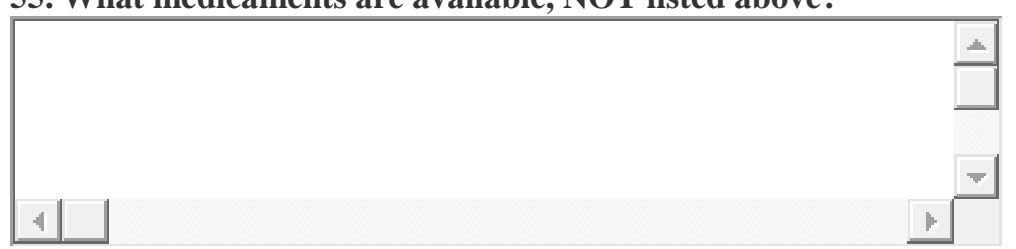

56. What are students taught to use for control of aerosol produced by the ultrasonic units?
Гigh volume suction
Г salvia ejectors
$\Gamma$ other, explain below

57. What are students taught to used for control of aerosol, NOT listed above?

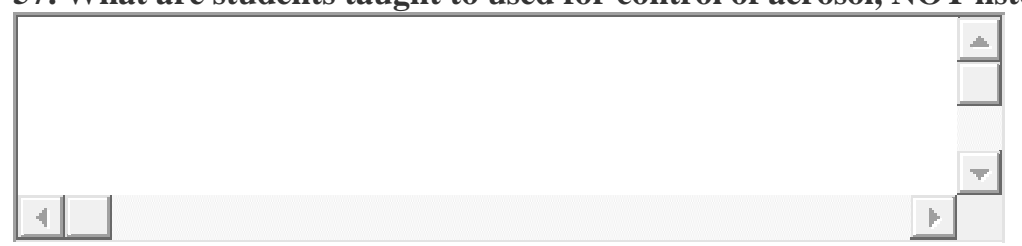

58. Are students required to administer a pre-procedural rinse to patients?

(C) Yes

No

59. What is used for the pre-procedural rinse?

$\Gamma$ essential oils mouth rinse

$\Gamma$ chlorhexidine gluconate rinse

ГNA

Г other, list below

60. What is used for the pre-procedural rinse, NOT listed above?

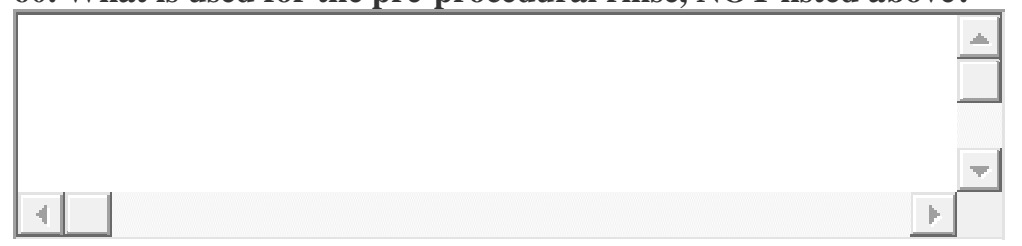

61. What methods are available for students to use for pain management? Mark all that apply.

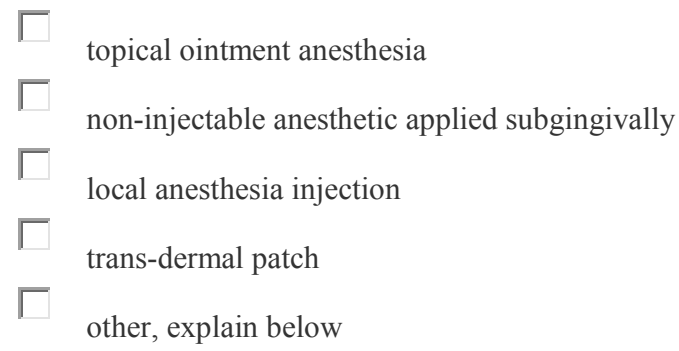


62. What methods, NOT listed above are available for students to use for pain management?

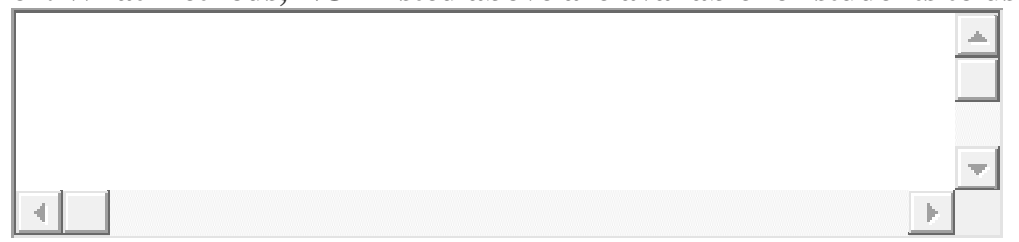

63. Does your program have student access to new technology? Mark all that apply.
Г endoscope
$\lceil$ loupes
「rush biopsy
$\lceil$ cavity detection device
$\lceil$ loupes with light
$\Gamma$ other, explain below

64. What other new technology do students have access?

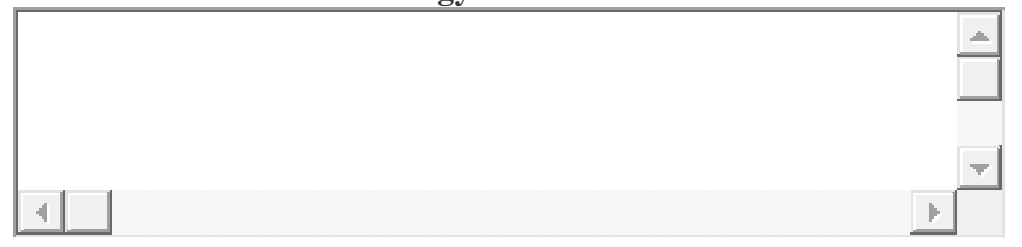

65. Comments:

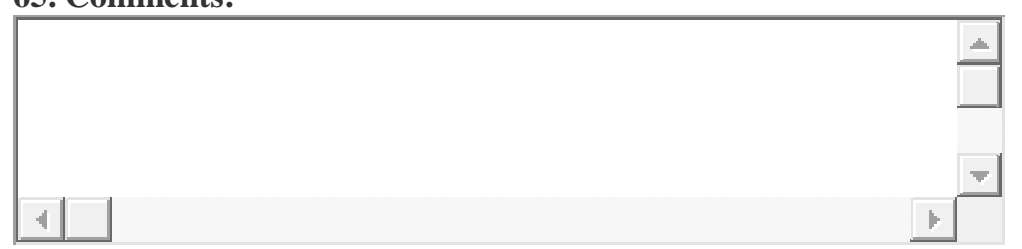

66. You may send any assessment materials or other information that you think may be useful in this study to my email address: sstempl2@ mix.wvu.edu 
APPENDIX C

First Email Request for Participation in Survey 


\section{APPENDIX C}

May 31, 2011

Dear Program Director,

This email is a request for you to participate in a research project, which is a requirement for completing my Master's of Science in Dental Hygiene. The title of the research is Ultrasonic Instrumentation Instruction in Dental Hygiene Programs in the United States. The following link will take you to my web page, which includes the official cover letter. By clicking on the consent box at the bottom of the letter, you will access the survey. The survey should take 15-20 minutes to complete. Please complete the survey by Tuesday, June 7 . Thank you.

\section{http://mysole.wvu.edu/sstempl2/survey cover letter.htm}

Sincerely,

Sharon Stemple Hinchman, RDH, BS

West Virginia University

Morgantown, WV 
APPENDIX D

Cover Letter 


\title{
West Vuginialiniversity
}

\author{
School of Dentisiry
}

April 25.2011

I Jeal I'roglam initector,

This email is a rejuest for you to parisipate in a rescarch project. to deternine das type and extent of

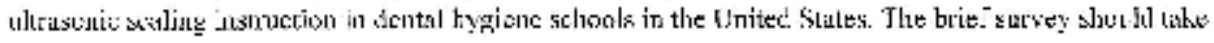
nomov than 5 maules.

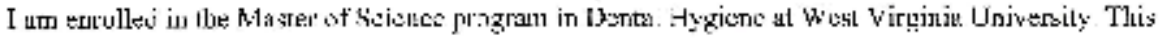

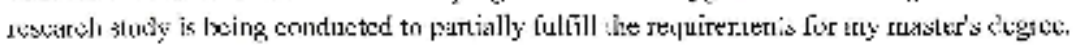

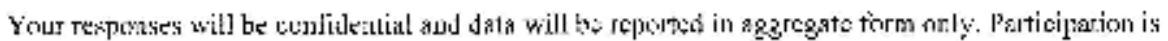

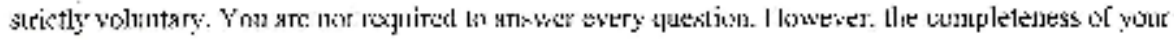

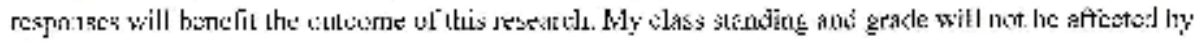
your sefusal to participxte in the smivey.

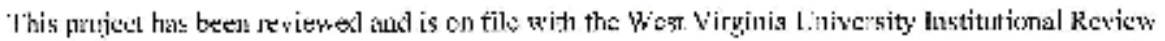
Buat:al,

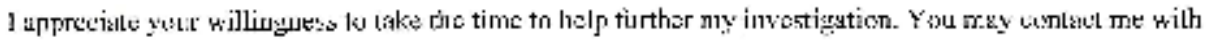

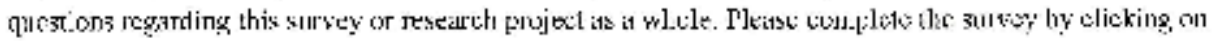

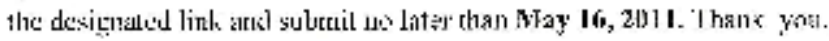

Sincerty.

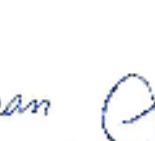

Siaron Stemple llinch rian, $\mathrm{BDH}_{i}$ B5 Graduate Studerit Division of uental Hyziene School of Dentistry sstempl2gmix.wusu-edu 3.94.635.7139
Diviain of Dental Hygisne

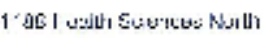

PO $3 \div$ \% 9425

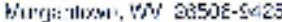
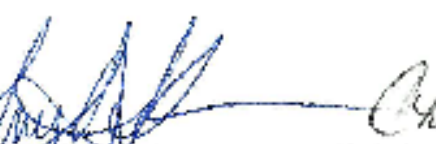

Christina DeBiase, EdD

Associate Dean for

Acaderric Al"dis
Interirr Director,

Divisin at Dental Hivgiense
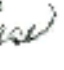


\section{APPENDIX E}

Second Email Request for Participation in Survey 


\section{APPENDIX E}

June 5, 2011

Dear Program Director,

This is a second email request for completion of a survey that was sent last week. If you have already completed the survey, thank you. The responses have been interesting and helpful. If you have not completed the survey, I urge you to participate in the survey.

This email is a request for you to participate in a research project, which is a requirement for completing my Master's of Science in Dental Hygiene. The title of the research is Ultrasonic Instrumentation Instruction in Dental Hygiene Programs in the United States. The following link will take you to my web page, which includes the official cover letter. By clicking on the consent box at the bottom of the letter, you will access the survey. The survey should take 15-20 minutes to complete. Please complete the survey by Wednesday, June 8 . Thank you.

\section{http://mysole.wvu.edu/sstempl2/survey_cover_letter.htm}

Sincerely,

Sharon Stemple Hinchman, RDH, BS

West Virginia University

Morgantown, WV 


\section{APPENDIX F}

Third Email Request for Participation in Survey 


\section{APPENDIX F}

June 10, 2011

\section{Dear Program Director,}

This is a third email request for completion of a survey that was sent last week. If you have already completed the survey, thank you. The responses have been interesting and helpful. If you have not completed the survey, I urge you to participate in the survey.

Iowa was inadvertently left out of the Midwest demographic, but has been corrected.

This email is a request for you to participate in a research project, which is a requirement for completing my Master's of Science in Dental Hygiene. The title of the research is Ultrasonic Instrumentation Instruction in Dental Hygiene Programs in the United States. The following link will take you to my web page, which includes the official cover letter. By clicking on the consent box at the bottom of the letter, you will access the survey. The survey should take 15-20 minutes to complete. Please complete the survey by Wednesday, June 15. Thank you.

\section{http://mysole.wvu.edu/sstempl2/survey_cover_letter.htm}

Sincerely,

Sharon Stemple Hinchman, RDH, BS

West Virginia University

Morgantown, WV 
Curriculum Vitae

Sharon Lee Stemple Hinchman

\section{Education}

Master of Science, Dental Hygiene, West Virginia University, Morgantown, WV, December 2011

Thesis: "Ultrasonic Scaling Instruction in Dental Hygiene Programs in the United States"

Advisor: Christina DeBiase, EdD

Additional Study:

Marshall University: Religious Traditions of the West, Contemporary Management

Davis \& Elkins College: Ecology, Genetics, Adolescent Psychology, Educational Technology

Certificate RESA VII: Substitute Teacher Training

Bachelor of Arts, Biology, Davis \& Elkins College, Elkins, WV. May 1979

Associate of Arts, Dental Hygiene, Allegany College, Cumberland, MD. May 1977

\section{Academic Service/Scholarly Activity}

Clinical Practicum: Clinical Instructor, senior dental hygiene students-spring 2010, junior dental hygiene students-fall 2010, senior dental hygiene students-spring 2011

DENT 711: Evening instruction of dental students in proper periodontal probing, PSR, charting, recording and documentation. April 2011, April 2010

Continuing Education Presenter: "Dimensions of the Diabetic Dental Patient," Mon Valley Dental

Hygienists' Association, Ruby Memorial Hospital, Morgantown, WV, April 2008

Davis Health Systems free athletic sports physicals-dental screenings. August 1999-2009

In Service Presenter: "Oral Health Care for Long Term Care Patients," Holbrook Nursing Home, staff in-service. Buckhannon, WV, August, 2006

Legislative: Met with WV Senators, Delegates and Lobbyists-General Supervision Bill, 2009

\section{Professional Affiliations}

American Dental Hygienists' Association (ADHA), current member

West Virginia Dental Hygienists' Association (WVDHA), current member

2011-2013 WVDHA Secretary

2007-2009 WVDHA Secretary, Reformatted WV Bylaws in Compliance with ADHA

2007 Nominee to the West Virginia Board of Dental Examiners

2006-2007 Component Delegate, Mon Valley Dental Hygiene Association

1986-1988 WVDHA Legislative Chair

1984-1986 WVDHA President

1982-1984 WVDHA President Elect

1982-1988 WVDHA Delegate to the American Dental Hygienists' Association

1978-1983 WVDHA Reporter to West Virginia Dental Association Journal

1979-1981 WVDHA Secretary

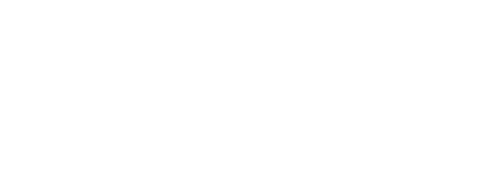

